Est Ag 52 (2017) 353-398

\title{
La experiencia religiosa. ¿Justifica la experiencia religiosa la creencia en Dios?
}

\author{
JAVIER ANTOLÍN SÁNCHEZ
}

RESUMEN: En este artículo vamos a analizar y estudiar los recursos y posibilidades de justificación de la creencia en Dios, y más en concreto, el Dios cristiano, basados en los argumentos que nos proporciona la experiencia religiosa. ¿Es racional creer o tener fe? ¿Pueden los cristianos justificar racionalmente sus creencias? Por ejemplo, ¿Pueden justificar que han experimentado la salvación de Dios por medio de Jesucristo? O tendremos que responder diciendo, que tal experiencia de Dios es muy personal y está más allá de la racionalidad. Lo que hemos pretendido examinar es que el creyente cristiano basado en su experiencia religiosa puede afirmar o justificar que su creencia religiosa es racional.

Palabras Clave: Experiencia, experiencia religiosa, racionalidad, justificación, creencia, epistemología religiosa, Alston.

ABSTRACT: In this survey we are going to analyze and study the resources and possibilities of justification of the belief in God, in particular, the Christian God, based in the arguments given by the religious experience. Is it rational believing or to have faith? May the Christians justify rationally their own beliefs? For example, May they justify that they have experienced the salvation of God through Jesus Christ? Or, we would have to answer saying that such experience of God is very personal and is beyond the rationality. We have tried to analyze is that the Christian believer based in his own religious experience could affirm and justify that his religious belief is rational.

KEYWORDS: Experience, religious experience, rationality, justification, belief, religious epistemology, Alston. 


\section{INTRODUCCIÓN}

Hay al menos dos modos posibles de justificar o de dar razón de la fe en Dios. Una es la llamada prueba evidencial y se ejemplifica por los tipos de justificación que proporcionan los argumentos tradicionales de la existencia de Dios (lo que podemos llamar teología natural); la otra es la de la experiencia y se supone que es suministrada por ciertas experiencias religiosas ${ }^{1}$.

Desde los años ochenta las discusiones filosóficas sobre la posible justificación de la creencia en Dios se han centrado más en los caminos de la experiencia religiosa que en las rutas del evidencialismo, en el que la racionalidad consiste en tener certeza para apoyar la creencia religiosa. Esta creciente valoración del elemento experiencial constituye para algunos una estrategia de inmunización frente a las críticas, mientras que para otros es una nueva forma de contacto con lo sagrado, una forma más genuina, inmediata, tal vez más fragmentada e individualista, pero, en cualquier caso más espontánea e inmediata. En este estudio vamos a analizar los recursos y posibilidades de justificación que nos proporciona la experiencia religiosa ${ }^{2}$.

Este volverse a la experiencia religiosa está motivado, en buena medida, por un interés por liberar la doctrina y la práctica religiosa de la dependencia de las creencias metafísicas. Aunque creemos que el camino experiencial puede tener su sentido en la actualidad, hemos de reconocer

1 Swinburne, Richard, La existencia de Dios, San Esteban, Salamanca 2011, 329. El argumento que parte de la experiencia religiosa afirma que las experiencias religiosas han ocurrido con frecuencia; que muchas personas han experimentado a Dios (o alguna cosa sobrenatural relacionada con Dios) y por ello conocen y pueden hablarnos de su existencia. Geivett, R. Douglas, "The Evidential Value of Religious Experience", en MeIster, Chad (ed.), The Philosophy of Religion Reader, Routledge, London \& New York 2008, 506. No se discute la existencia de las experiencias religiosas. Lo que se debate es si las experiencias religiosas son verificables o, si es razonable creer que algunas experiencias religiosas son reales, y que, por lo tanto, sea razonable creer en la existencia de Dios basado en estas experiencias. Proudfoot, Wayne, Religious Experience, University of California Press, Los Angeles 1985, xiii. La religión se basa en un momento de experiencia que es intrínsecamente religioso, por lo tanto no necesita justificarse por un argumento metafísico, por el tipo de prueba que consideran los que defienden el argumento del diseño.

2 Audi, Robert, "Religious Experience and the Practice Conception of Justification", en SEnor, D. Thomas, (ed.), The Rationality of Belief and the Plurality of Faith, Cornell University Press, New York 1995, 127. BAGger, C. Matthew, Religious Experience, Justification, and History, Cambridge University Press, New York 1999, 1-2 y 109. El estudio se centra tanto en la importancia que han tenido en nuestros días las experiencias religiosas como justificación racional de las creencias religiosas, como últimamente para negar las creencias religiosas. 
ciertas reservas, pues no podemos olvidar que la religión no se puede reducir a la experiencia religiosa, pues en el hecho religioso hay gran variedad de conceptos, ideas, experiencias, creencias; todo ello constituye la religión, ya que no se puede reducir únicamente al aspecto más vivencial o afectivo.

En este sentido, conviene decir ya antes de nada, que aunque nos centramos en la experiencia religiosa no podemos olvidar que ésta no es la cima del fenómeno religioso. El momento cumbre es la actitud religiosa fundamental, lo que podemos llamar -desde nuestra tradición cristiana- la actitud teologal. Pues el peligro de poner en el centro la experiencia religiosa es que al ser ésta un fenómeno psíquico que reviste externamente la condición de actividad del sujeto afectado por un objeto, se pierde de vista la propiedad inevitable de trascendencia que corresponde a la respuesta religiosa y con ella la condición absolutamente trascendente del Misterio, que es el término de la misma 3 .

A la hora de estudiar el fenómeno religioso, lo primero no es la dimensión subjetiva o el llamado polo antropológico de la religión, donde se revela la obra del hombre como respuesta a la irrupción del llamado polo teológico -lo sagrado, el misterio- en su experiencia y en su vida en general. Solamente aparece la dimensión subjetiva o la experiencia religiosa porque el polo teológico -el Misterio- se manifiesta y hace posible la experiencia religiosa. No hay experiencia religiosa sin la presencia o irrupción del Misterio o de lo sagrado en la vida humana.

Ahora bien, hemos de decir que dado que el Misterio se nos presenta como una realidad absolutamente transcendente, totalmente otra, suprema e inefable, y no podemos tener acceso a ella directamente, por eso, desde nuestra situación, lo más accesible es la experiencia religiosa; de ahí que cada vez haya cobrado más importancia en el estudio del hecho religioso esta dimensión, pero no podemos olvidar que la experiencia religiosa se da porque el Misterio se hace presente en la vida humana ${ }^{4}$.

3 Martín Velasco, Juan, Introducción a la fenomenología de la religión, Trotta, Madrid $^{6}$ 2006, 175.

${ }^{4}$ Ibid., 163. Sin el Misterio no habría religión, aunque para que exista la religión es necesario una respuesta a la presencia del Misterio. La realidad del Misterio es suprema con las realidades mundanas, pero también y sobre todo en relación con el hombre. Es decir, el hombre no puede disponer de esa presencia en absoluto, no puede dominarla, objetivarla, ni poseerla con ninguno de sus actos. Para que la realidad suprema aparezca sin perder su condición, el hombre debe renunciar a hacer de ella un objeto de sus actos y debe establecer una relación en la que admita que el centro de la misma no es él, sino esa realidad suprema. El centro de la religión es el reconocimiento de la absoluta supremacía del Misterio. 
Por otra parte, en la vida humana hay gran variedad de experiencias, ahora bien reconocemos que la religiosa es especial ${ }^{5}$, una experiencia que podemos reconocer como única. Esta es considerada extraña y obscura, inaccesible a los caminos ordinarios de la investigación. No es fácil dar una definición escueta de experiencia religiosa ${ }^{6}$, es básicamente una experiencia que alguien tiene y que está relacionada con su vida religio$\mathrm{sa}^{7}$. Tenemos innumerables ejemplos. En la historia de las religiones abundan los testimonios de individuos que afirman que han tenido visiones de Dios, o han experimentado la unidad del Brahmán, o han visto un ángel, o han hablado en lenguas, o han tenido miedo ante la presencia de Satanás, o han experimentado una conversión desde la muerte espiritual a la vida. Innumerables personas de distintos credos y culturas han afirmado que han tenido esta clase de experiencias esotéricas o numinosas 8 .

Algo esencial que se pone de manifiesto al estudiar la experiencia religiosa, es que el hombre religioso no parte de sus necesidades o deseos ni encuentra en Dios a un ser que responde remediando sus necesidades y saciando esos deseos. El Misterio o la realidad divina, no es un fin que

5 Vide Rodríguez, Vicente, ¿En qué Dios Creemos?, PPC, Madrid 2008, 33. La aplicación del término "experiencia" al mundo de la religión comporta bastantes dificultades derivadas sobre todo del hecho de que la religión siempre dice referencia a algo de alguna manera sobrenatural o más allá de lo sensible. HART, Kevin, "Introduction", en Hart, Kevin - Wall, Barbara (eds.), The Experience of God. A postmodern Respond, Fordham University Press, New York 2005, 12. La experiencia de Dios desde un punto de vista lógico es imposible, pues no podemos experimentar lo que por definición trasciende los fenómenos.

${ }^{6}$ SwINBURNE, La existencia, 332-333. Lo que hace de una experiencia una experiencia religiosa es la manera en que le parece al sujeto, es decir, la persona cree que en esa experiencia Dios está presente, o que esa experiencia es causada porque Dios está presente.

7 Alston, William, Perceiving God. The Epistemology of Religious Experience, Cornell University Press, Ithaca \& London 1993, 34-35. La experiencia religiosa puede abarcar la totalidad de la propia vida religiosa -el propio pensamiento, el razonamiento, las dudas y visiones sobre Dios y nuestra relación con él, nuestros esfuerzos por vivir la vida cristiana, lo mismo que nuestros éxitos y fracasos en esta empresa, etc.-. Alston tiene un concepto más restringido de la experiencia religiosa, abarca solamente a aquellas experiencias en las que parece que Dios se muestra o se presenta a alguien. Esta es una de las razones por las que evita el concepto de experiencia religiosa. Muchas discusiones se han dado respecto a si la experiencia religiosa es cognitiva, si es esencialmente un asunto del sentimiento, o se reduce solamente a las "experiencias cumbre", si ocupa un papel central en la religión, o si proporciona evidencia para las creencias religiosas, etc.

${ }^{8}$ Meister, The Philosophy, 473. Martin Velasco, Introducción, 176. El primer dato a tener en cuenta en el estudio de las experiencias religiosas es su existencia, indudable, y de la que existen testimonios unánimes en todas las tradiciones religiosas. En todas ellas existen personas que en un momento $u$ otro de su vida dicen haberse encontrado con el Misterio, haber sido visitados por Dios, haber tenido la conciencia indudable o el sentimiento vivísimo de haber entrado en contacto con él. 
el hombre busque espontáneamente, sino una realidad que le precede y de cuya presencia él toma conciencia. Para el verdadero hombre religioso, Dios no responde a ninguno de sus deseos, ya que todos estos tienen por objeto una realidad mundana, que representa un contexto enteramente nuevo. Por eso, cuando el hombre se encuentra con él, descubre la felicidad, pero una felicidad distinta de la que se basa en la satisfacción de sus deseos'.

La reflexión filosófica sobre la experiencia religiosa ofrece multitud de preguntas, aunque no vamos a responder a todas, intentaremos ahondar en la problemática planteada. Por ejemplo, ¿qué es la experiencia religiosa? ¿Podemos considerar esas experiencias como auténticas? ¿Cuál es la causa o el origen de la experiencia religiosa? ¿Cómo distinguir la experiencia religiosa de otro tipo de experiencias? ¿Proporciona la experiencia religiosa evidencia para la creencia religiosa o, más en concreto, para la existencia de Dios? ¿Puede esa experiencia proporcionarnos evidencia para creer en Dios o en la Realidad última? Estas son algunas de las preguntas que trataremos de abordar en las páginas que siguen.

\section{LA EXPERIENCIA RELIGIOSA}

Una experiencia ${ }^{10}$ es un acontecimiento que la persona vive (bien como participante o bien como un observador) y sobre lo que uno es consciente. Cuando hablamos de experiencia ${ }^{11}$ sin calificativo nos referi-

${ }^{9}$ Martín Velasco, Introducción, 165. SAn Martín, Javier - SÁnChez, Juan José, "Una prolongada navegación por el tema religioso. Conversación con Manuel Fraijó", en San Martín, Javier - SÁnchez, Juan José (eds.), Pensando la religión. Homenaje a Manuel Fraijó, Trotta - UNED, Madrid 2013, 71. Por lo tanto, frente a la crítica de Feuerbach y Freud de que la religión brota de la necesidad, de la precariedad, de la indefensión humana frente a la muerte, también podríamos añadir que "la religión existe porque tenemos que vivir". De este modo, la creencia religiosa tiene un matiz positivo: pues no surgiría solo por el miedo a la muerte, sino de la afirmación de vida. En el origen de la religión estaría la experiencia de un encuentro con algo o con Alguien que ilumina la vida y le da su sentido último. La religión se apoyaría en una experiencia vital, en el encuentro del ser humano con una realidad enteramente diferente que le llena de vida y le trasciende.

10 Proudfoot, Wayne, "Rational Belief and Religious Experience," en Geivett, R. Douglas - SweEtMan, Brendan (ed.), Contemporary Perspectives on Religious Epistemology, Oxford University Press, New York - Oxford 1993, 345; Proudfoot, Religious, 216217. El término experiencia es ambiguo. Cuando nos preguntamos sobre lo que una persona ha experimentado en un cierto momento, podemos entenderlo de dos modos: $1^{\circ}$ ) como le pareció a la persona en ese momento y $2^{\circ}$ ) la mejor explicación que se puede dar de esa experiencia. Esta ambigüedad está presente en nuestra conversación ordinaria sobre la percepción. A veces una persona, por ejemplo, puede creer haber visto un oso, pero la 
mos a tener un conocimiento concreto, inmediato de la vida, de algo que se goza, sufre, padece, etc. Experiencia supone una relación personal con algo o con alguien, haber pasado por algo, haber vivido, sentido, hecho' ${ }^{12}$. Experimentar es probar y descubrir las cosas, con lo que se consigue un conocimiento de ellas. Quiere decir aprender a través del contacto directo con los hombres y las cosas, descubrir y percibir lo real. En la experiencia aparecen dos aspectos: las cosas y el sujeto que la experimenta. Este carácter relacional entre el sujeto que experimenta y el objeto experimentado es el principio constitutivo de toda experiencia en cuanto que esta es apertura del sujeto a una realidad exterior a la que él tiene acceso. Toda experiencia implica un carácter subjetivo, único y singular, irrepetible y personal, y al mismo tiempo hace referencia a una dimensión objetiva exterior ${ }^{13}$. El conocimiento por experiencia se opone en todos los casos al que otros me procuran y al conocimiento por abstracción y mediante ideas o conceptos generales.

El objeto de la experiencia religiosa en el contexto cristiano en el que nos vamos a centrar consiste en la relación amorosa con Dios, que se puede describir con diferentes términos: encuentro, relación o comunión de amor con Dios. Cada vez se insiste más en el encuentro con Dios o en la experiencia del encuentro con Dios ${ }^{14}$.

La experiencia religiosa es interior e individual, y únicamente quienes la realizan tienen acceso directo a ella, algo parecido a lo que ocurre con la experiencia de dolor. La "experiencia experiencial" supone la implicación de la totalidad de la existencia personal en la realidad de lo "experimentado". Algo específico de la experiencia religiosa es que, en un instante,

reinterpretación de la experiencia, le lleva a concluir que lo que vio realmente no fue un oso, sino un tronco de leña. La percepción de un objeto como un oso era una explicación, pero fue reemplazada por una explicación mejor, al obtener mayor información. Esa mejor explicación condujo a una reinterpretación de la experiencia.

11 Gelabert, Martin, Valoración cristiana de la experiencia (=Nueva Alianza 115), Sígueme, Salamanca 1990, 20. Experiencia es conciencia de realidad, impresión de realidad, acceso a la realidad. En ella el sujeto queda afectado por la realidad, se insinúa de esa manera el papel indispensable que juega el sujeto. Estamos hablando de toda realidad: no sólo los objetos externos al hombre, sino también los fenómenos de la propia actividad interior.

12 Gelabert, Valoración, 9.

13 Vide Rodríguez, ¿En qué Dios, 33. Yandell, E. Keith, The Epistemology of Religious Experience, Cambrige University Press, New York 1993, 42. Una experiencia es un estado consciente en el que el sujeto (fenomenológicamente) parece ser consciente de un aspecto o de un objeto.

14 Por citar dos referencias de los últimos papas: Benedicto XVI en su encíclica Deus Caritas est, $\mathrm{n}^{\circ} 1$ y el Papa Francisco en su exhortación apostólica Evangelii Gaudium n ${ }^{\circ} 3$. 
quien tiene la experiencia reúne en su propio 'aquí y ahora' la totalidad de la realidad, por esta razón, en la experiencia religiosa se revela el sentido en la situación histórica concreta del hombre que la realiza.

En la experiencia permanece una categoría epistemológica que enriquece la humanidad y que no puede reducirse a la función cognitiva o discursiva. Una persona experimentada es la que tiene muchas habilidades en el campo de la percepción y de la intuición. El conocimiento experimental no es sólo un conocimiento sobre la realidad, sino también sobre un cierto modo de enfrentarse con la realidad. La experiencia religiosa se refiere al modo en que el homo religiosus experimenta la realidad ${ }^{15}$.

Las experiencias religiosas se diferencian de las ordinarias en que lo que se experimenta es considerado por la persona como la presencia de un ser sobrenatural16 (Dios mismo o la manifestación de Dios en alguna acción), un ser relacionado con Dios (una manifestación de Dios o un personaje como la Virgen María) o algo como una Realidad Última indescriptible (tal como no dual Absoluto [Brahmán] o el nirvana).

Las experiencias religiosas afectan a todo hombre y repercuten en todos los niveles de su condición, pues tienen lugar en el centro mismo de la persona ${ }^{17}$. La experiencia religiosa concierne al sujeto y repercute sobre todas las facultades humanas y desencadena sentimientos muy intensos y peculiares, de paz, sosiego, sobrecogimiento. Las experiencias religiosas tienen su rasgo más característico en lo que se suele designar como su radical pasividad. Porque en todas ellas el sujeto de la relación se descubre a sí mismo como sujeto más pasivo que activo, o mejor, activo con una actividad que consiste en aceptar, recibir, reconocer la realidad del Misterio, que tiene la iniciativa de la relación, que antes incluso de cualquier acción es percibido por el sujeto como quien genera la presencia del propio sujeto ${ }^{18}$.

15 Geybels, Hans, Cognitivo Dei Experimentalis. A Theological Genealogy of Christian Religious Experience, Leuven University Press, Leuven 2007, 5.

16 Proudfoot, "Rational", 346 y 349. El aceptar una experiencia como religiosa incluye la creencia de que no puede interpretarse exhaustivamente en términos naturales. La marca distintiva de la experiencia religiosa es que dicha experiencia solo puede explicarse en términos religiosos. Y es, precisamente, esta creencia y la identificación del sujeto de su experiencia bajo una descripción particular, la que la hace religiosa.

17 STOKER, Wessel, Is Faith Rational? A Hermeneutical Phenomenological Accounting for Faith (=Studies in Philosophical Theology), Peeters, Leuven 2006, 14-15. La experiencia religiosa afecta a toda la persona, en su corazón, sentimientos, pensamientos y conducta. Stoker define la experiencia religiosa como la implicación de toda la persona con la trascendencia.

18 Martín Velasco, Introducción, 566-567. Esta actitud que se encarna y expresa en las experiencias religiosas, supone una ruptura radical con la actitud que rige en la rela- 
Algunas experiencias se pueden llamar "intrínsecamente religiosas", pues comportan unos factores muy espirituales: como el sentido de la presencia o actividad de un ser o poder santo no físico, la aprehensión de una "realidad última" más allá del mundo de los cuerpos físicos; y el sentido de consecución del sumo bien del hombre, la última dicha, liberación, salvación, o "mi verdadero yo" que no es alcanzable con las cosas de este mundo. Y a diferencia de las experiencias de paz, alegría y otras, es imposible que este tipo de experiencia no sea religiosa. Estas características no presuponen la intervención de una deidad consciente. Algunas experiencias religiosas se describen en el modo que sugiere la intervención divina; otras sugieren que Dios está actuando por medio de causas naturales, o que el mundo y la naturaleza humana están constituidos de tal modo que con un esfuerzo apropiado, podemos obtener la salvación por nosotros mismos ${ }^{19}$.

Las experiencias religiosas más frecuentes entre la gente ordinaria son las llamadas experiencias regenerativas. Estas, como el mismo nombre sugiere, tienden a renovar la fe del sujeto y mejorar su bienestar espiritual, moral, físico y psicológico; es como recargar las baterías espirituales. Aquí se incluyen una amplia gama de experiencias: una esperanza nueva, fuerza, confort, paz, seguridad y alegría, vistas como religiosas porque se obtienen durante una actividad religiosa como la oración, ocasionadas por un poder divino, o acompañada por un sentido de una presencia divina; experiencias de ser guiado, llamado, perdonado, y "salvado", generalmente por un poder externo divino; experiencias de curación, y experiencias de sentirse ayudado divinamente en las virtudes morales y en el amor por los otros y el descubrimiento del "sentido" en la vida. La mayoría de la gente religiosa encuentra que su fe se sostiene en tales experiencias; estas son algunas de

ción con los objetos del mundo. Si frente a todos ellos el hombre se comporta como sujeto que los pone frente a sí, los observa, conoce, domina, utiliza y desea, es decir, se sirve de ellos para conseguir la satisfacción de sus necesidades, enriquecerse y en definitiva realizar de la mejor manera su propia condición de sujeto, en esta nueva relación, para entrar en contacto con lo verdaderamente supremo, es decir, lo superior a todo y al mismo hombre, éste tiene que comenzar a salir de sí mismo, descentrarse y reconocer su centro en esa nueva realidad. (p. 567).

${ }^{19}$ Franks Davis, Caroline, The Evidential Force of Religious Experience, Oxford University Press, New York 1989, 30-31. Algunas de estas experiencias son: los seres humanos tienen un 'verdadero ser' que está más allá del 'yo fenoménico', y este 'verdadero ser' está íntimamente relacionado con la naturaleza divina, que hay un poder santo que está más allá del mundo de los sentidos, el cual es percibido como lo último, el fundamento unitario del ser, como algo más que brilla en el mundo natural, y como una presencia personal y amorosa, y los seres humanos pueden encontrar su satisfacción más profunda en una relación armoniosa con este poder santo (p. 239). 
las características que hacen a la religión viva, más que la mera aceptación de una serie de doctrinas o la realización de ciertos rituales ${ }^{20}$.

Los místicos de todas las tradiciones religiosas son personas que han "visto", han "oído", han "gustado", en una palabra, han entrado en contacto con la realidad última: Dios, lo Divino, el Misterio. Esa relación ejercida, vivida, padecida, se resume en una experiencia o relación experiencial. Dicho con otras palabras, el místico es alguien que ha entrado en contacto personal, vivido, con la realidad última a la que todas esas "piezas" del sistema remiten. El místico se caracteriza, en primer lugar, por vivir personalmente, y, en este sentido, experimentar el reconocimiento de esa Presencia de las que viven las religiones ${ }^{21}$.

John Hick ${ }^{22}$ quiere demostrar que para aquellos que han experimentado en sus vidas la presencia de Dios y aceptan esta experiencia como verdadera, la creencia en Dios estaría fundamentada por la experiencia de vivir en la presencia de Dios. Hick no busca un argumento para la existencia de Dios, sino más bien la racionalidad de la creencia en Dios, basado en la experiencia religiosa teísta, es decir, quiere justificar las creencias religiosas basándose en la experiencia religiosa. Por lo que para las personas que tienen experiencias religiosas intensas sería razonable creer en la existencia de Dios.

Mirando la historia podemos ver cómo creer en la realidad de Dios ha sido racional para gente en el pasado, lo es ahora en el presente y probablemente lo será también en el futuro, es decir, a lo largo de la historia ha habido personas que han vivido, viven o vivirán una relación personal con Dios. Hick rememora entre otras la experiencia de Jesús de Nazaret, que experimenta la presencia de Dios como Abba, un ser de voluntad amorosa. La presencia de Dios era tan real para Jesús de Nazaret como

${ }^{20}$ Franks Davis, The Evidential Force, 44-45. Geybels, Cognitivo Dei, 452. En este estudio histórico queda demostrado que la experiencia religiosa cristiana se define de distintos modos en la historia de la cristiandad. La experiencia religiosa cristiana es un concepto que ha sido continuamente contextualizado a lo largo de los veinte siglos de cristianismo.

21 Martín Velasco, Juan, El fenómeno místico. Estudio comparado, Trotta, Madrid 1999, 289; El fenómeno, 293. Este primer rasgo, común a todas las formas del fenómeno místico, para nosotros un místico es alguien que, en relación con la realidad última a la que remiten todos los elementos del fenómeno religioso -en el caso de las místicas religiosas- y en relación con la realidad que fundamenta la vida y que envuelve la totalidad de los seres del mundo -en el caso de las místicas profanas- ha mantenido en algún momento una relación personal vivida que le lleva o le ha llevado a decir: "lo he visto con mis propios ojos": "A partir de ahora y pase lo que pase, ya sé".

22 Hick, John, "Rationality of the Religious Belief", en GeivetT - Sweetman, Contemporary Perspectives, 304-319. 
la existencia de sus vecinos, los montes, los ríos o el lago de Galilea. Jesús experimentó al Padre del cielo como una realidad viviente, y el suponer que no existiera, sería tan absurdo como sospechar que una persona con la que ha estado hablando tampoco 23.

De este modo, se puede justificar la creencia en la existencia de Dios del mismo modo que justificamos las creencias sobre lo que existe y cómo son las cosas. Para que nosotros creamos en la realidad de las cosas que se nos presentan a nuestra experiencia, ya sea directamente (las cosas que vemos), como indirectamente (la experiencia de vivir la presencia de Dios invisible), tienen que cumplirse dos condiciones. Primero, que hemos juzgado responsablemente (o razonablemente) que es posible la existencia de esa entidad. Segundo, que se da en nuestra experiencia de una manera tan poderosa, persistente e intrusiva que exige la creencia en su realidad. Cuando alguien cree en Dios basado en una experiencia religiosa tan concluyente, se puede decir que esa creencia es razonable o está fundamentada racionalmente. Por lo tanto, para las personas que tienen una experiencia religiosa irresistible y penetrante de Dios, como Moisés, Jesús de Nazaret, Pablo, Francisco de Asís, Madre Teresa, etc., sería racional creer en la existencia de Dios basado en esa experiencia religiosa.

Hick se pregunta, ¿qué decir de los creyentes ordinarios que no gozan de experiencias religiosas tan incontrastables? Es cierto que si pertenecemos a la misma tradición religiosa, las personas pueden tener una experiencia de vivir en la presencia de Dios, y la pueden considerar como base para su creencia religiosa. Pero por otro lado, también podría pensarse que la experiencia es ilusoria en conjunto. Por eso, en esas circunstancias, la persona religiosa puede confiar su propia experiencia a la más larga corriente de la experiencia de la que forma parte, es decir, nuestra experiencia religiosa puede motivarse por la confianza en las grandes figuras religiosas de nuestra tradición religiosa. Las personas ordinarias pueden ajustar su experiencia y confiar en la experiencia, creer y vivir sobre esta misma fundamentación ${ }^{24}$.

Como estamos viendo, a veces hablamos de la experiencia religiosa en general, pero nos vamos a concentrar especialmente en la experiencia religiosa cristiana. Mencionemos la descripción ya clásica de esta experien-

23 Hick, "Rationality," 308.

24 Hick, "Rationality," 312-313. El creyente puede afirmar que Dios existe, porque Jesús también lo afirmaba. No solamente el cristianismo, todas las grandes religiones se han estructurado siempre en tradiciones a partir de un personaje excepcional (Moisés, Jesús de Nazaret, Mahoma, Buda), de un "místico" en el sentido más estricto, que gozó de 
cia que nos relata William James, como veremos la concepción intelectual de la experiencia religiosa se ha mutado en una concepción emocional:

Dios es más real para mí que cualquier otro pensamiento, cosa o persona. Siento verdaderamente su presencia y vivo en tan íntima armonía con sus leyes como si estuviesen escritas en mi cuerpo y en mi alma, lo siento cuando llueve y cuando hace sol. Lo que mejor describe mis sentimientos es un temor reverencial mezclado con un estado de reposo delicioso. Hablo con Él como un compañero de oración, y rezo intensamente, y nuestra comunión es muy grata, siempre me responde, a menudo con palabras dichas tan claramente que parece que mi oído externo oiga el susurro, pero en general lo hace mediante fuertes sacudidas mentales. Normalmente leyendo un texto de las escrituras que expone una nueva visión de Él y de su amor por mí, y su preocupación por mi seguridad. Podría poner centenares de ejemplos, en materias de estudio, problemas sociales, dificultades financieras, etc. Nunca olvido que Él es mío y yo soy suyo; es una alegría permanente. Sin Él la vida sería un vacío, un desierto, un erial sin costas ni caminos 25 .

Seguramente que miles de cristianos subscribirían algo parecido o idéntico a lo aquí descrito.

W. James a veces compara la experiencia religiosa a la experiencia sensorial. Caracteriza la experiencia religiosa como un sentido de algo más, algo más allá de lo mundano en el orden de un sentido de presencia. Esta analogía, como veremos después, se ha convertido en algo central en las discusiones sobre la experiencia religiosa. El centro de la argumentación de los recursos de justificación para la experiencia religiosa se resume en tres afirmaciones ${ }^{26}$ :

1. Los estados místicos, cuando están plenamente desarrollados, normalmente son, y tienen derecho a serlo, una autoridad absoluta para

un peculiar acceso al Misterio. La experiencia excepcional del místico fundador ha sido modélica para sus seguidores. Este argumento no es un argumento de autoridad. La fuerza está en que se apela a una experiencia excepcional. El cristiano tiene buenos argumentos históricos para afirmar que Jesús de Nazaret tuvo una "experiencia de Dios" que podemos calificar como superior a la que puede tener el cristiano ordinario. Jesús vivió su vida en coherencia absoluta con esta experiencia del Misterio. Por otra parte, el cristiano encuentra en su propia experiencia una cierta semejanza con la experiencia de Jesús.

25 JAMES, William, Las variedades de la experiencia religiosa, Península, Barcelona 1986, 64.

26 Ibid., 317-321. 
el individuo que visitan. James argumenta diciendo que nuestras propias creencias racionales están basadas en una evidencia de naturaleza similar a la que los místicos aducen como propia. Las experiencias místicas son percepciones tan directas, para quienes las tienen, como cualquier sensación lo pueda ser para nosotros. Es decir, los estados místicos proporcionan justificación para las creencias religiosas.

2. De los estados místicos no emana ninguna autoridad que convierta el deber de aceptar acríticamente sus revelaciones por quienes quedan al margen de ellos. Es decir, los místicos no tienen derecho alguno a exigir que aceptemos sus peculiares experiencias si nosotros quedamos al margen y no nos sentimos estimulados por ellas.

3. Los estados místicos, frente a la verdad que nos viene por el entendimiento y los sentidos, abren la posibilidad de otros órdenes de verdad en los que podemos continuar libremente creyendo. Los estados místicos añaden simplemente un significado más allá de lo sensible o de la consciencia.

Audi 27 interpreta a James concluyendo que ciertas experiencias místicas -incluyendo paradigmas de lo que comúnmente llamamos experiencias religiosas- normalmente producen creencias justificadas sobre su objeto aparente. Y aunque no lo dice, incluiría proposiciones teístas justificadas, como que el poder de Dios está presente en el mundo y que su amor nos envuelve.

Vamos a seguir estudiando qué es una experiencia religiosa y si hay algo común para describir todas las experiencias religiosas, y si realmente es legítimo utilizar la experiencia religiosa para justificar nuestras creencias religiosas. Al menos, podemos decir que es necesario hacer un estudio crítico de las experiencias religiosas como apoyo para defender las afirmaciones o doctrinas religiosas 28 .

Queremos profundizar y responder a la pregunta, ¿qué es en realidad la experiencia religiosa? Más en concreto, ¿qué clase de experiencia es? Para ello vamos a ver, en primer lugar, los distintos modos de experiencia religiosa.

27 Audi, "Religious," 135.

28 Franks, DAVIS, The Evidential Force, 2. Esta revaloración de la experiencia tiene que ser interdisciplinar, es decir, la experiencia tiene que ser examinada por las diversas ciencias, pero tiene que ser también multicultural, es decir, tenemos que estudiar y analizar las experiencias religiosas de las diferentes religiones. 


\section{TIPOS DE EXPERIENCIAS RELIGIOSAS}

\section{La experiencia religiosa como sentimiento}

Friedrich Schleiermacher (1768-1834) sostuvo que la experiencia religiosa no es una experiencia cognitiva o intelectual, sino "un sentimiento de absoluta y total dependencia de una fuente o poder que es distinta del mundo". Esa experiencia es auténtica por sí misma, intuitiva y no mediada por conceptos, ideas, creencias o prácticas. Y dado que es un sentimiento, es anterior a las distinciones conceptuales, no podemos describirla. Es una experiencia más afectiva que cognitiva.

"La religión está enraizada en un momento de experiencia que es intrínsecamente religiosa, así no necesita justificarse por argumentos metafísicos, por la clase de evidencia considerada por los defensores del argumento del diseño, o por apelación a su importancia para la vida moral. Además, porque la religión es autónoma, cualquier conflicto posible entre religión y ciencia o moralidad se excluye. Cualquier intento por asimilar la religión a los fenómenos no religiosos es un intento por reducirlo a alguna otra cosa. El reduccionismo es así el principal error a evitar en el estudio de la religión ${ }^{29} "$.

Esta visión influyó en muchos, incluyendo a Rudolf Otto (1869-1937). Otto está de acuerdo en que existe un lado de Dios que puede ser captado por la razón. Por analogía podemos atribuir a Dios propiedades tales como espíritu, propósito, buena voluntad, omnipotencia, y personalidad propia ${ }^{30}$. "Todos estos atributos constituyen conceptos claros y definidos: ellos pueden ser captados por el intelecto, pueden ser también analizados por el pensamiento, incluso admiten una definición." Pero en relación a la naturaleza más profunda de Dios -su santidad-no puede ser conocida racionalmente; es inefable. Debemos pues comprender la santidad de Dios por algo que va más allá de la razón, es decir, por el sentimiento.

${ }^{29}$ Schleiermacher, Frederich, Sobre la religión, Tecnos, Madrid 1990.

30 OTто, Rudolf, Lo santo. Lo racional y lo irracional en la idea de Dios, Alianza editorial, Madrid 2005, 9. Para toda idea teísta de Dios, pero muy singularmente para la cristiana, es esencial que la divinidad sea concebida y designada con rigurosa precisión por predicados tales como espíritu, razón, voluntad, voluntad inteligente, buena voluntad, omnipotencia, unidad de sustancia, sabiduría y otros semejantes; es decir, por predicados que corresponden a elementos personales y racionales que el hombre posee en sí mismo, aunque en forma más limitada y restringida. 
La experiencia religiosa es un sentimiento, o mejor, un conjunto de sentimientos. Este sentimiento se presenta de muchas maneras:

"El tremendo misterio puede ser sentido de varias maneras. Puede penetrar como un suave flujo el ánimo, en la forma de sentimiento sosegado de la devoción absorta. Puede pasar como una corriente fluida que dura algún tiempo y después se ahíla y tiembla, y al fin se apaga, y deja desembocar de nuevo el espíritu en lo profano. Puede estallar de súbito en el espíritu, entre embates y convulsiones. Puede llevar a la embriaguez, al arrobo, al éxtasis... ${ }^{31}$ "

Otto encuentra manifestaciones de lo numinoso en tres sentimientos específicos. Hay un sentimiento de dependencia, de que somos meras criaturas, es decir, "sentimiento de la criatura de que se hunde y anega en su propia nada y desaparece frente a aquel que está sobre todas las criaturas $^{32}$." Existe el sentimiento de miedo religioso y de estar aturdido ante el mysterium tremendum. Temblamos y nos estremecemos ante la vista de Dios. Y finalmente, tenemos un sentimiento de deseo del ser transcendente que nos fascina. Se construye en nosotros un sentimiento de inquietud y deseo de Dios.

La afirmación de William James de que el sentimiento es la fuente más profunda de la religión implica que la reflexión filosófica y teológica son productos secundarios, extensiones de la experiencia ${ }^{33}$. Y es muy cierto que si no hubiera experiencia religiosa, no habría ni teologías ni filosofías religiosas. La religión siempre ha sido algo relacionado con la experiencia. La religión no es solamente un conjunto de creencias y una colección de ritos, sino que todas estas creencias y prácticas religiosas están profundamente enraizadas en la vida de las personas y las comunidades $^{34}$.

Ahora bien, aunque la reflexión filosófica sea un producto secundario, y lo primero de la religión sea el sentimiento, puesto que somos seres que pensamos no podemos excluir el intelecto de cualquiera de nuestras funciones, por lo tanto de alguna manera el sentimiento viene mediado por nuestro pensamiento. Incluso en el soliloquio con nosotros mismos interpretamos nuestros sentimientos intelectualmente. Además, al hablar o expresar nuestros sentimientos, debemos hacerlo utilizando fórmulas

\footnotetext{
31 Ibid., 22.

32 Ibid., 18.

33 JAMES, Las variedades, 323.

34 Proudfoot, Religious, xi.
} 
verbales abstractas y generales ${ }^{35}$. Aunque el sentimiento sea necesario para la religión y, en cierto modo, es lo primero, el carácter y valor del sentimiento ha de ser determinado por el contenido racional de la religión.

Frente al sentimiento, que es solamente válido para el individuo, tenemos la razón que es válida universalmente. La teología que se basa en la razón e intenta convencer a los hombres universalmente. Del mismo modo, la filosofía tiene pretensiones de fundamentar la religión en la razón universal ${ }^{36}$.

Uno de los problemas en el análisis de la experiencia religiosa es que es difícil ver cómo podemos generar afirmaciones religiosas cognitivas verdaderas, como las que encontramos en la filosofía y la teología, desde sentimientos no cognitivos. Si tanto lo experimentado como las experiencias son inefables, y si lo último es tan fundamental que precede a las distinciones cognitivas, ¿qué verdades religiosas se siguen de ello? Incluso los intentos por describir la experiencia por analogía presuponen que el acontecimiento pueda ser comprendido cognitivamente, para que se pueda apreciar que las analogías son apropiadas a la experiencia y las que no lo son.

Y de hecho, podemos decir que no se pueden entender las afirmaciones de Schleiermacher del sentimiento de dependencia absoluta y lo numinoso de Otto sin las creencias y prácticas de la cultura religiosa en la que se inspiran, en concreto, en el Dios creador y providente que procede de la biblia hebrea y de la tradición cristiana. Por lo tanto, sin rechazar lo que pueda corresponder al sentimiento dentro de la experiencia religiosa, no se pueden entender estas experiencias religiosas sin las creencias y prácticas religiosas previas $^{37}$.

Una objeción es que los defensores de esta visión no han comprendido la naturaleza de los sentimientos y las emociones. Las emociones no son más fundamentales que las creencias o el comportamiento. De hecho, del mismo modo que las creencias y las acciones, las emociones dependen de conceptos. Lo que queremos decir es que la emoción no puede especificarse sin referencia a los conceptos. Para explicitar una emoción

35 JAMES, Las variedades, 324.

36 Ibid., 327.

37 Proudfoot, "Rational Belief", 349-350; Religious, 233-236. La experiencia, la creencia o la práctica religiosas solamente se pueden comprender desde dentro de la tradición religiosa. Por eso, todos los intentos de restringir la reflexión filosófica o teológica al análisis interno falla porque las doctrinas y experiencias para ser analizadas asumen conceptos y creencias que no son característicamente religiosos. 
es necesario especificar la cualidad del sentimiento, el objeto de la emoción y las razones por las que el sujeto justifica la emoción.

Pero de algún modo la religión siempre remite a la experiencia, ya que los procesos conceptuales pueden clarificar hechos, definirlos, interpretarlos, pero no los producen. Siempre hay un plus, un aquello, del que sólo el sentimiento puede responder. Así pues, la filosofía en esta esfera tiene una función secundaria que no puede garantizar la veracidad de la $\mathrm{fe}^{38}$.

Por lo tanto, si los conceptos son parte constitutiva de las emociones, la experiencia religiosa no puede estar completamente divorciada de los elementos cognitivos ${ }^{39}$. Tenemos pues que reconocer que la experiencia religiosa está constituida por conceptos y creencias, por eso no hay dificultad para comprender la experiencia de personas y comunidades que están histórica y culturalmente muy separadas del intérprete. Como los conceptos y creencias son constitutivos de la experiencia, un estudio cuidadoso de los conceptos en una cultura particular nos permite acceder a la variedad de experiencias que pueden tener las personas en una determinada cultura ${ }^{40}$.

\section{La experiencia religiosa como experiencia perceptual}

Un segundo punto de vista es considerar la experiencia religiosa como un tipo de percepción. William Alston (1921-2009), por ejemplo, sostiene que la experiencia religiosa tiene la misma estructura de la percepción. En nuestra percepción sensorial ordinaria, cuando vemos, por ejemplo un gato, hay tres elementos: la persona que ve el gato (el que percibe), el gato que es visto (el objeto percibido) y la apariencia del gato (el fenómeno). Del mismo modo, se sostiene, que hay tres elementos en la experiencia religiosa: el sujeto de la experiencia religiosa (quien tiene dicha experiencia), Dios o la realidad última que se experimenta, y la apariencia o la presentación de Dios al que tiene la experiencia.

Hay un enérgico debate filosófico sobre cómo hay que analizar la percepción. En particular, las cuestiones se presentan en relación al status del fenómeno. Pero hay un acuerdo general de que en la percepción,

38 JAMES, Las variedades, 340.

39 Peterson, Michael - Hasker, William - Reichenbach, Bruce - Basinger, David, Reason \& Religious Belief. An Introduction to the Philosophy of Religion, Oxford University Press, New York - Oxford 1991, 17. Proudfoot, Religious, 228-229.

40 Proudfoot, "Rational Belief", 347. 
los objetos se nos presentan de tal modo que nos posibilitan conocerlos. Similarmente, Dios se nos presenta en la experiencia religiosa de tal modo que nos permite conocerle a él y a sus acciones.

Alguno podría pensar que es extraño comprender la experiencia religiosa como un tipo de percepción, pues hay diferencias importantes entre la percepción ordinaria, la experiencia sensorial y la experiencia religiosa. La percepción sensorial es una experiencia común, mientras que la experiencia religiosa es menos común, incluso, podemos decir que es anómala. La experiencia sensorial reporta información sobre el mundo, mientras que la experiencia religiosa comporta aparentemente poca información sobre Dios. Todos los seres humanos tienen capacidad para la percepción sensorial, en cambio parece que muchos no tienen capacidad para la experiencia religiosa ${ }^{41}$. Estas diferencias, sin embargo, no muestran que la experiencia religiosa tenga una estructura distinta de la percepción. Pero algo es cierto, ni la frecuencia de la experiencia ni la cantidad de información que ofrece nos dice algo sobre su estructura. Además, hay mucha gente, como los ciegos o sordos, que tienen limitaciones en sus capacidades sensoriales, pero ese hecho no proyecta ninguna duda sobre la afirmación de que ver u oír sea una forma de percepción. De modo similar, el hecho de que muchos no tengan experiencias religiosas, no desaprueba la afirmación de que la estructura de la experiencia religiosa es semejante a la perceptual ${ }^{42}$.

Hay sin embargo una diferencia significativa que se alega para mostrar la falsedad de la tesis de que la experiencia religiosa es un tipo de percepción ${ }^{43}$. Concierne a la naturaleza de la apariencia perceptual o presentación (el fenómeno). En la percepción ordinaria sensorial el objeto percibido se nos presenta como portador de ciertas cualidades sensoriales. Las cosas que percibimos en nuestra vida ordinaria tienen cualidades sensoriales. En cambio, aquellos que tienen experiencias religiosas informan que lo que perciben, en concreto Dios, no presenta cualidades sensoriales. Las cualidades que experimentan en Dios son la bondad, el poder, el amor, la soberanía y la fortaleza. Como señalamos arriba, a

41 Alston, Perceiving, 36.49. Geivett, "The Evidential Value", 517, nos recomienda rebajar la afirmación de que hay una paridad epistémica fuerte entre la percepción sensorial y la experiencia de Dios que aparece en el argumento estándar. Ya que hay también disparidades entre la percepción sensorial y la experiencia de Dios; y algunas tienen consecuencias epistemológicas sustanciales.

42 Peterson, Reason, 18.

43 Franks Davis, The Evidential Force, 22. Solamente las experiencias religiosas perceptuales pueden ofrecer evidencia directa para una realidad religiosa más allá de la mente de los creyentes. 
veces la experiencia religiosa tiene un contenido sensorial, pero normalmente ese contenido procede del que media en la experiencia (por ejemplo, puestas de sol y símbolos) en vez de la experiencia directa (Dios). Pero las características de la puesta de sol no son las cualidades de Dios. El problema entonces es este: si las características de lo que es percibido supuestamente (el fenómeno) son tan diferentes en el caso de la experiencia religiosa, ¿No será un error comprender la experiencia religiosa como una forma de percepción?

Alston acepta que las cualidades percibidas en las experiencias religiosas de Dios - propiedades como poder, belleza, y bondad- no son sensoriales. Algunas de estas, por ejemplo, se refieren a las disposiciones o actitudes de Dios que siguen a sus acciones. Sin embargo, para Alston eso no significa que no puedan ser el contenido de una percepción. Distingue entre cualidades fenoménicas (el modo que algo me aparece en el momento) y las cualidades objetivas (la disposición de un objeto para verlo en ciertas circunstancias). Cuando describimos un objeto experimentado, afirma, frecuentemente, que nuestra descripción se refiere a las propiedades objetivas y no a las fenoménicas. No describimos el objeto diciendo cómo la cosa aparece en el momento, el listado de los datos que recibimos de los sentidos- por ejemplo, que mi casa aparece como amarilla sombría y blanca, y más amarilla oscura en las sombras, trapezoidal por debajo del tejado, y así sucesivamente. Si hacemos eso, la descripción del objeto en cada experiencia sería indefinidamente larga. A menudo, hablamos sobre las cualidades de la cosa usando conceptos comparativos. Es decir, describimos el objeto de nuestra experiencia diciendo como nos aparecería en condiciones normales ${ }^{44}$.

De modo similar, las cualidades como el poder, la bondad y el amor se presentan sin usar conceptos sensoriales, sino conceptos comparativos. Ellas muestran cómo Dios pudiera aparecer en ciertas condiciones. Si nuestra experiencia de Dios se describe usando conceptos comparativos, hay una distinción paralela entre el modo que presentamos los objetos de la percepción sensible y nuestra percepción de Dios. Frecuentemente informamos de nuestra percepción de cosas sin usar conceptos extraordinarios, sino al contrario, usando conceptos del fenómeno -por ejemplo, diciendo que lo que percibimos se parece a un perro, o sabe a caramelo. Del mismo modo, las noticias de nuestra experiencia de Dios apelan a la comparación más que a los conceptos del fenómeno. Por supuesto, hay todavía una cuestión relacionada con las cualidades del fenómeno que

44 Peterson, Reason, 18-19. 
caracterizan nuestra experiencia de lo divino, que el experimentador religioso no necesita determinar, pero no es frecuente para las personas tener experiencias sensoriales de cosas sin ser capaces de especificar qué sean o deban ser propiedades constitutivas del fenómeno.

Conocemos cómo las casas, los coches y los árboles aparecen en las circunstancias normales y nos proporcionan la descripción relevante del fenómeno. Últimamente las propiedades objetivas son también del fenómeno, pero se puede objetar, ¿cómo es posible que los que tienen la experiencia religiosa sepan cómo aparecería Dios en circunstancias normales, si no pueden proporcionarnos una descripción fenoménica de él? Alston sugiere que nuestra experiencia con las personas que son más o menos buenas nos da alguna idea de cómo experimentar a Dios mostrando su bondad. Aquí, de nuevo, estaríamos moviéndonos desde un punto de comparación que contiene información sensorial (cómo se comporta la gente buena) a un punto que le falta (cómo actúa Dios). Estas son precisamente las razones bajo las que nosotros conocemos, por ejemplo, qué es una almohada, cuando decimos que este objeto que tenemos enfrente se parece a una almohada. En resumen, la ausencia de conceptos fenoménicos en las experiencias de Dios presenta dificultades para entender la experiencia religiosa como una experiencia perceptual.

La cuestión en relación a cómo se mostraría Dios da lugar a un segundo problema. Mientras hay una consistencia general en relación a las percepciones humanas sensoriales y podemos revisar la exactitud de algunas percepciones particulares apelando a otras experiencias perceptuales, las experiencias religiosas presentan una gran diversidad. Por lo tanto, la exactitud de alguna experiencia particular no puede confirmarse fácilmente. Las experiencias religiosas están condicionadas por las distintas perspectivas religiosas y culturales, por eso hay una gran diferencia en lo que la gente percibe en las diferentes religiones. La Realidad Última que experimenta un hindú es muy diferente del Dios que experimenta un cristiano ${ }^{45}$.

Por supuesto que esto no muestra necesariamente que la experiencia religiosa no sea perceptual; podría solamente significar que las experiencias religiosas están más abiertas a la interpretación individual.

\footnotetext{
45 Ibid., 20.
} 


\section{La experiencia religiosa como explicación sobrenatural ${ }^{46}$}

Los defensores de este tercer punto de vista rechazan la tesis de que las experiencias religiosas sean perceptuales. Hablar de una experiencia perceptual conlleva una afirmación no sobre la conciencia que tiene la persona sobre el acontecimiento (algo tiene que habérsele presentado o aparecerle al que percibe), sino sobre la causa que provoca la experiencia. Para que nuestras experiencias sean realmente percepciones, el objeto percibido debe estar allí y hacer una contribución causal (de manera correcta) para nuestra experiencia. Por ejemplo, decir que una persona ve un gato es conceder que hay un gato y que el gato es la causa de que la persona lo vea. Si el gato no existe y no es la causa de la percepción, entonces decimos que la persona no percibe a un gato, al contrario, que tiene la alucinación de ver un gato, o que se equivoca, al considerar que lo que ve sea un gato.

Si la experiencia religiosa es un tipo de experiencia perceptual, las mismas condiciones deben mantenerse como verdaderas. Es decir, si la experiencia religiosa es perceptual, lo que es percibido debe existir y debe ser la causa (de manera correcta) de nuestra percepción. Ahora bien, si restringimos nuestra consideración a cómo las personas interpretan sus experiencias (que podría llamarse una descripción fenomenológica), no habría problema en usar el modelo de la percepción para comprender la experiencia religiosa. Tales personas creen que realmente han percibido a Dios, su actividad, o algún ser relacionado con él. El encuentro con Dios o con la Realidad Última es, para ellos, una experiencia religiosa.

Sin embargo, describir objetivamente las experiencias religiosas como experiencias perceptuales sería demasiado restrictivo. Si queremos ser generosos en permitir que gente de diversas creencias tengan experiencias religiosas, esta formulación nos compromete a creer que los objetos o causas de aquellas experiencias religiosas existan realmente. Es decir, no podríamos aceptar que alguien tuviera una experiencia religiosa sin admitir que Dios o la Causa Última existen. Para evitar este resultado insatisfactorio, Wayne Proudfoot (1939-) mantiene que nuestra caracterización de la experiencia religiosa debe ser suficiente amplia para aceptar

46 BAgGer, Religious, 13-16. En la actualidad cada vez es más difícil aceptar explicaciones sobrenaturales, tenemos una tendencia a juzgar nuestro pensamiento en relación a nuestros propios estándares, por eso las explicaciones históricas, culturales y naturales son las que se imponen. Aunque se acepte la legitimidad de las explicaciones sobrenaturales, desde la modernidad se levantan sospechas sobre dichas explicaciones, por lo que la explicación natural toma la precedencia. 
que la gente tenga experiencias religiosas que se describen en términos de la creencia que han experimentado algo sobrenatural, sin que haya que conceder que exista tal objeto sobrenatural.

Una experiencia religiosa es una experiencia que la persona interpreta como religiosa. Tomar una experiencia como religiosa significa que los experimentadores creen que la explicación naturalista de la experiencia es insuficiente, y solamente puede explicarse en términos de doctrinas religiosas ${ }^{47}$. Por ejemplo, las personas que afirman tener experiencia de Dios rechazarán cualquier intento para localizar la causa de la experiencia en sus procesos digestivos, emociones, deseos de cumplimiento o en el subconsciente. Ellos solamente pueden comprender a Dios en el diálogo o en el encuentro personal.

Según esta opinión, es importante distinguir la descripción de la experiencia, de la explicación de la experiencia. En la descripción de la experiencia domina la perspectiva del sujeto. Las experiencias religiosas no pueden describirse fuera del sistema de creencias, incluyendo la creencia de que existe el objeto experimentado. Eso significa que la descripción de una experiencia religiosa incluirá una consideración causal de un acontecimiento que invoca la existencia de lo sobrenatural. Por ejemplo, no se puede describir la experiencia que tuvo san Agustín sin referencia a su creencia de que Dios existe y que puede comunicarse. Las consideraciones científicas (ya sea de las ciencias sociales o naturales) son irrelevantes para describir la experiencia religiosa, se necesita una explicación sobrenatural.

Sin embargo, el hecho que los experimentadores comprendan la experiencia en términos de lo sobrenatural no quiere decir que realmente experimenten lo sobrenatural o que no exista una explicación natural de su experiencia. Podría haber sucedido que, aparte de alguna actividad o intención divina, un niño cerca estuviera jugando a un juego en el que una canción particular decía "toma y lee". Sin embargo, aunque esto fuera verdad, no haría la experiencia de Agustín menos religiosa. Simplemente significa que él tomó como última causa -al mismo Dios- aunque pudiera no haber sido esa causa. En otras palabras, una experiencia puede ser una experiencia religiosa auténtica aunque no se perciba un objeto sobrenatural. Todo lo que se requiere es que los que tienen la experiencia interpreten sus experiencias en términos de categorías y creencias sobre lo sobrenatural.

\footnotetext{
47 Proudfoot, Religious, 217.
} 
Toda experiencia está influenciada por conceptos y creencias y es conformada por el lenguaje. Cuando los experimentadores tienen una experiencia, identifican la experiencia bajo alguna clase de conceptos o reglas. No hay dato experimentado que no esté interpretado o que no se interprete más tarde. La misma experiencia está incrustada en ambos, en alguna interpretación del mundo y en algún compromiso para una cierta clase de creencias y prácticas religiosas. Por ejemplo, los místicos están comprometidos en la creencia de que su experiencia religiosa de Dios es inefable y comunica conocimiento sobre Dios. Esto significa que no habrá ninguna descripción de las experiencias religiosas.

Pero, ¿Cómo evaluar que la persona tuvo una experiencia genuina? Si la experiencia religiosa está formada por los conceptos y creencias de cada persona, ¿cómo determinar que sea -la natural o la sobrenatural- la que proporciona la mejor explicación? Proudfoot está en lo cierto cuando argumenta que, aunque alguien desde fuera (Jane) describa la experiencia que tiene Joe en términos de las creencias sobre el mundo y su causa, Jane no necesita tener esas creencias; pero tiene que conocer que el sistema de creencias, en este caso de Joe, es el que proporciona la estructura apropiada para explicar lo que sucede.

Se puede evaluar la veracidad de las afirmaciones de la experiencia religiosa dentro de un sistema particular de creencias. Es decir, la explicación de la experiencia debe ser internamente consistente con la clase de creencias y conceptos que el experimentador utiliza. Es imposible para las personas con un sistema de creencias diferente al que tiene la experiencia religiosa evaluar esas afirmaciones, por faltarles el tipo de conceptos y creencias que usa el experimentador; no están en condiciones de evaluar la explicación dada por el experimentador.

\section{LA EXPERIENCIA RELIGIOSA SEgún William Alston}

Alston ${ }^{48}$ reconoce que su tesis central está en contradicción total con las suposiciones que son universalmente compartidas en los círculos inte-

48 Senor, The Rationality, 2. Con el libro Percieving God, Alston ha dado a la comunidad filosófica uno de los más importantes libros del siglo en relación a la epistemología de la creencia religiosa. La experiencia religiosa que el creyente toma por ser una experiencia directa de Dios puede, sostiene Alston, proporcionar prima facie justificación para la creencia teísta tanto como la creencia que se forma según una práctica teísta socialmente establecida. Lo que hace que ese libro sea tan singular es que está escrito por una figura significativa de la epistemología contemporánea y que, a su vez, es también versado en la teología clásica, la teología contemporánea y en el misticismo. 
lectuales. A menudo, los sabios del mundo -creyentes o no creyentesconsideran que la "experiencia religiosa" es un fenómeno puramente subjetivo. El propósito de su libro es desafiar esa suposición ${ }^{49}$.

Alston ${ }^{50}$ sostiene que la experiencia religiosa ${ }^{51}$ o la percepción de Dios $^{52}$ juegan un papel epistémico importante en relación a las creencias sobre Dios; análogo al jugado por la percepción sensorial con respecto a las creencias sobre el mundo físico ${ }^{53}$. Alston no afirma que la experiencia religiosa sea el único modo de conocer a Dios, al igual que la percepción

49 Alston, Perceiving, 4. Es contrario a la afirmación de que la experiencia mística consiste simplemente en sentimientos o sensaciones subjetivas (p. 67).

50 Conviene aclarar que Alston se centra en el concepto de Dios desarrollado en las religiones teístas -judaísmo, cristianismo e islam-. Es decir, los ejemplos de la experiencia o percepción de Dios están tomados de estas tradiciones. En concreto, se centra en la tradición cristiana, pues es la que mejor conoce y a la que pertenece.

51 Plantinga, Alvin, Warranted Christian Belief, Oxford University Press, New York 2000, 182-183. Hemos de decir que el término "experiencia religiosa" se construye y emplea de modo diferente para cubrir una amplia y confusa variedad de casos; el problema es que es un término que como sugiere Alston es preferible no utilizar. No obstante, podemos decir lo siguiente: el sensus divinitatis siempre envolverá la presencia de una experiencia de una u otra clase, incluso aunque la imagen sensorial no esté siempre presente. A veces hay una imagen sensorial, a veces es un sentimiento de la presencia de Dios, donde parece que no hay una imagen sensorial, pero quizás algo (realmente difícil de describir); a menudo hay un tipo de experiencia que se relaciona con un sentimiento de miedo, sentimiento de gratitud, delicia, locura, enfado, agradecimiento y otros parecidos. Un componente común en estas experiencias es un tipo de miedo, un sentimiento de lo numinoso, un sentimiento de estar en la presencia de un ser de majestad y grandeza irresistible.

52 Plantinga, Warranted, 180-181. Alston piensa que la supuesta percepción de Dios, a menudo, no comporta imágenes sensoriales (de hecho Alston afirma que se centra en la variedad no sensorial de la percepción mística). Ahora bien, lo que Alston llama "percepción" hay que entenderlo en el sentido analógico del término. Para el creyente la presencia de Dios es palpable. Un número sorprendente de gente afirma que en un tiempo u otro han sentido la presencia de Dios, o -al menos que les parece que sienten la presencia de Dios- aunque este sentimiento no lo comprendan como imagen sensorial. Muchos otros dicen que escuchan a Dios cuando les habla, etc.

53 HASKer, William, "The Epistemic Value of Religious Experience: Perceptual and Explanatory Models," en SENOR, The Rationality of Belief, 150-151 y 168-169. La percepción sensorial es universalmente considerada como uno de los modos mejor acreditados para adquirir la creencia. El modelo perceptual nos proporciona grandes ventajas para la racionalidad de la creencia religiosa. Por lo tanto, debemos dar importancia al valor epistémico de la experiencia religiosa y concluir que sin la contribución de la experiencia nos sería difícil construir una justificación satisfactoria de la creencia religiosa. GEIVETT, "The Evidential Value", 508. Alston establece una analogía estrecha entre la percepción sensible y lo que llama "percepción mística" y argumenta que la experiencia mística se puede construir en el mismo sentido genérico del término como percepción sensorial. La analogía entre la percepción sensible y la percepción de Dios asegura una paridad epistemológica fuerte entre la evidencia de la percepción sensible para fundamentar creencias sobre el mundo físico y la percepción de Dios para fundamentar las creencias sobre Dios. 
sensorial no es el único modo de conocer el mundo físico (el razonamiento científico, por ejemplo, llega a la conclusión de que no podemos ir más allá de las afirmaciones justificadas por la percepción sensible). Pero la percepción sensorial es la base esencial para nuestro conocimiento sobre el mundo físico y, de un modo similar, la experiencia religiosa es la base esencial para el conocimiento de Dios o que dicha experiencia nos pueda proporcionar justificación para ciertas creencias sobre Dios ${ }^{54}$.

No obstante, Alston ${ }^{55}$ reconoce el valor epistemológico de la experiencia religiosa, pero este no es el valor fundamental de la experiencia religiosa. Pues desde un punto de vista religioso y, en concreto, desde el punto de vista cristiano, el valor principal de la experiencia de Dios es que nos permite entrar en una relación personal con él; y, lo que es más importante aún, nos hace regocijarnos de la comunicación amorosa con Dios para la que fuimos creados. Aunque es significativo el valor epistemológico de la percepción mística y en esto se centra su libro, no piensa que este enfoque sea lo más importante para la vida religiosa. Al contrario, según la tradición cristiana el significado principal de la percepción mística es que es una parte integral de la relación personal con Dios que es el objetivo fundamental de la vida humana.

Lo que estamos considerando es si la experiencia religiosa puede proporcionar algún fundamento para la creencia religiosa, si puede servir para justificar la creencia religiosa o contribuye a la racionalidad de la creencia cristiana. Por eso comparamos la epistemología de la experiencia religiosa con la epistemología de la experiencia sensible. Tenemos que distinguir primero entre la experiencia que proporciona directamente justificación para una creencia, y la que proporciona justificación indirecta ${ }^{56}$.

54 Alston, Perceiving, 3. La gente a veces percibe a Dios o tiene experiencia de Dios y por eso adquiere creencias justificadas sobre Dios. Del mismo modo que no son los hechos internos sobre la experiencia sensible los que nos proporcionan el argumento efectivo para la existencia de los objetos físicos externos, sino que es, por el contrario, nuestra experiencia sensible de los objetos físicos externos nos ayuda a que nos formemos varias creencias justificadas sobre ellos. De ese mismo modo, nuestra experiencia de Dios nos lleva a argumentar o adquirir creencias justificadas sobre la existencia de Dios.

55 Ibid., 2.12.63. El cristianismo tiene consideraciones teológicas que apoyan la idea que es posible para los seres humanos percibir a Dios. Hay un énfasis en la doctrina y el pensamiento cristiano sobre la manera que Dios nos ha creado para que vivamos en comunión de amor con él. Estamos seguros que esta tesis es compatible con la idea que tal comunión está reservada para la vida después de la muerte, pero hay referencias en la Biblia y en el pensamiento cristiano que apuntan en la dirección opuesta (Jn 14, 23). Si es posible la comunión entre Dios y el hombre, entonces cada parte debe percibir al otro pues de otra manera difícilmente tendría lugar la mencionada "comunión de amor".

56 AUdi, "Religious", 135. Las experiencias indirectas tienen lo que llamamos una base naturalista, en el sentido que Dios es percibido por medio -o quizás en- de algún ob- 
Una creencia se justifica indirectamente, cuando proporciona justificación para algunas creencias, que por su parte justifican la otra creencia. Así he aprendido indirectamente por experiencia que el vino de Ribera de Duero es afrutado, porque he experimentado que esta, esa, y aquella botella de Ribera de Duero es afrutada, y estas proposiciones apoyan la generalización. La justificación experiencial directa en términos del estar justificado por parte del sujeto, en virtud de tener la experiencia, al estimar que lo que está experimentando es tal y cual. Por ejemplo, la experiencia visual de tener un ordenador situado enfrente de mí en estos momentos, me permite afirmar que dicha experiencia esté directamente justificada ${ }^{57}$.

Encontramos afirmaciones de justificación directa e indirecta de las creencias religiosas. Cuando alguien cree que su modo de relacionarse con el mundo tras su conversión, ha de explicarse mediante las gracias sobrenaturales del Espíritu Santo, esa persona supone que su creencia de que el Espíritu Santo le da la gracia está directamente justificada por la experiencia. Cuando, por otra parte, alguien estima que está experimentando la presencia de Dios, piensa que su experiencia le justifica el suponer que está experimentando a Dios.

Estamos estudiando si la experiencia religiosa ${ }^{58}$ puede proporcionar una justificación directa para la creencia religiosa. En el sentido más amplio, 'experiencia religiosa' abarca cualquier experiencia que uno tenga en conexión con su vida religiosa, incluyendo alegrías, temores, anhelos, o lo que uno tenga en un contexto religioso. Pero aquí nos ocupamos de las experiencias que justifican directamente las creencias religiosas. Es decir, nos estamos refiriendo a la presencia y acción de Dios en nuestra propia vida -que Dios nos está hablando, reconfortando, dándonos su fuerza y coraje, guiándonos, derramándonos su amor o alegría, sosteniéndonos en el ser-, etc.

jeto natural o algún acontecimiento. Las experiencias directas, al contrario, significan que son vistas como autónomas perceptualmente: Dios se muestra al sujeto pero no en o por medio de una apariencia natural.

57 Alston, Perceiving, 21. La presentación directa es cuando el objeto está directamente presente o inmediatamente presente para el sujeto, aquí la presentación indirecta sería una contradicción en términos. Pero podemos distinguir entre ver algo directamente a verlo en un espejo o en la televisión. A esta última la llamamos percepción indirecta, dado que no vemos a la persona directamente sino a través de la percepción de un objeto. Aplicado a Dios sería la percepción de Dios tamizada por la percepción de algo (el cielo estrellado, las montañas, etc.).

58 Ibid., 35. Hay muchas discusiones sobre si la experiencia religiosa es cognitiva, es esencialmente un asunto de sentimiento, o está confinada a especiales "experiencias cumbre," juega un papel central en la religión y provee evidencia para las creencias religiosas. 
Este tipo de creencias religiosas que son justificadas directamente por la experiencia religiosa, Alston las llama M-creencias ${ }^{59}$ (de M manifestación). Es decir, son creencias no sobre la divinidad de Dios ${ }^{60}$, sino sobre cómo se percibe la naturaleza de Dios (Dios se experimenta como ser, entonces decimos que es bueno, poderoso, glorioso, que tiene la plenitud y la sabiduría) y sobre las actividades de Dios (cuando Dios se experimenta actuando, es decir, hablando, perdonando, dando fuerza, compadeciéndose) que se manifiestan en nuestras vidas ${ }^{61}$. Estas creencias están más abiertas a recibir el apoyo, pues son creencias de cómo la naturaleza y las actividades de Dios se manifiestan en nuestras vidas, en vez de ser afirmaciones desnudas sobre la divinidad en sí misma ${ }^{62}$.

Alston se concentra en las experiencias religiosas que disfrutan los creyentes devotos ordinarios, es decir aquellos que no han experimentado una gran disciplina contemplativa, ni han tenido una visión inmediata de Dios. Esto significa que deja a un lado el grueso de la literatura filosófica sobre la epistemología de la experiencia religiosa, que se concentra, demasiado estrechamente, en la experiencia mística. Realmente la experiencia mística clásica ha atraído mucha atención, y además la obsesión por esta experiencia ha conducido a un serio descuido de la epistemología del cristiano ordinario.

59 Ibid., 1. La tesis central del libro es que el conocimiento experimental de Dios (experiencia de Dios) o la percepción de Dios que llama Alston contribuye a la fundamentación de la creencia religiosa. Una persona puede justificar ciertas creencias sobre Dios si percibe a Dios en su ser, o actuando (p. 77). Las M-creencias son una clase particular de creencias perceptibles basadas en la percepción mística, en el sentido de que Dios tiene alguna propiedad perceptible o está envuelto en alguna actividad perceptible.

60 Véase Plantinga, Warranted, 117 y 331 . Aunque las M-creencias no son específicamente creencias cristianas, pueden apoyar las creencias cristianas sobre Dios. La experiencia religiosa no puede mostrar de modo específico que existe un Dios personal, y mucho menos creencias cómo que Dios reconcilia todas las cosas en Cristo.

61 Alston, William, "Christian Experience and Christian Belief", en Plantinga, Alvin - WolsterstorfF, Nicholas (ed.), Faith and Rationality, University Notre Dame Press, Notre Dame - London 1983, 103. Aunque no podemos encontrar confirmación del mensaje cristiano por nuestra propia experiencia, tendríamos mucha menos justificación en aceptar dicho mensaje si no hubiéramos experimentado la comunión con Dios, ni le hubiéramos oído hablar, o sentir su fuerza e influencia del Espíritu Santo. Es decir, la experiencia de vivir la vida cristiana contribuye a fundamentar y dar racionalidad a nuestras creencias cristianas.

62 FranKS DAVIS, The Evidential Force, 22. La experiencia de sentir que Cristo está cerca y me conforta, no dice nada sobre el sujeto externo o acontecimiento, sino del modo como las cosas le parecen al sujeto. Creyentes y no creyentes aceptarían que el sujeto tuvo esa experiencia, por lo tanto tendríamos un punto de partida incontrovertible para construir el argumento. 
No obstante, Perceiving God ${ }^{63}$ se centra en la "experiencia mística ${ }^{64 "}$ o "percepción mística" accesible al cristiano ordinario, es decir, no en las experiencias místicas extraordinarias. El foco de su estudio serán las experiencias directas de Dios, pero no sensoriales. Estas experiencias comportan una presentación, o algo que se le aparece al sujeto y éste lo interpreta como Dios. Según esta teoría, la percepción es la conciencia de la aparición de algo a alguien como tal, una relación inanalizable, no reducible a la conceptualización de un objeto. La conciencia de la experiencia directa de Dios es un modo de percepción (aunque para ser veraz, Dios debe existir y estar propiamente relacionado con el sujeto). Un requerimiento plausible para la percepción verídica de Dios es que este debe estar entre las causas de esa experiencia; se argumenta que no tenemos razón para excluir esa posibilidad. La afirmación de que la gente a veces percibe a Dios se defiende también contra varias objeciones ${ }^{65}$. No aspiro a probar la autenticidad de la percepción de Dios, que requeriría que probáramos la existencia de Dios y su papel en la producción de las experiencias en cuestión. El objetivo es también rebatir las objeciones a la convicción de que los sujetos tienen directamente conciencia de Dios, y señalar que su convicción es correcta, y la toman propiamente por estar percibiendo a Dios ${ }^{66}$.

Como podemos ver, Alston rememora la importancia que tiene el tono afectivo en la experiencia religiosa y considera la posibilidad de que

63 Alston, Perceiving, 5.

$64 \mathrm{Ibid}$., 22. Alston examina lo que llama percepción mística o (equivalente) "la percepción directa de Dios". En general, si uno percibe directamente X entonces "uno es consciente de X" por medio de un estado de consciencia que se distingue de X, y puede ser hecho un objeto de una conciencia inmediatamente absoluta pero no es percibido.

65 Ibid., 96. Se duda de que sea posible reconocer algo que alguien ha experimentado como Dios. Pero la gente está convencida de que experimenta a Dios, aunque es dudoso que alguien pueda saber, o justificar que cree esto. $\mathrm{Y}$ hay bases sólidas para estas dudas.

66 Ibid., 49-50. Algo preocupante es la posibilidad que el contenido de la percepción mística consiste totalmente en cualidades afectivas, diversos modos que el sujeto interpreta como estar en la presencia de Dios. No hay duda que tales experiencias son afectivas. Los sujetos hablan de éxtasis, dulzura, amor, delicia, gozo, contento, paz, reposo, arrobamiento, temor y maravilla. Nuestra incapacidad para especificar alguna otra clase de cualidades fenoménicas no sensoriales conduce naturalmente a la sospecha que la experiencia se limita a reacciones afectivas para una presencia creyente no dejando lugar para la presentación experimental de Dios o alguna otra realidad objetiva. WYNN, R. Mark, Emotional Experience and Religious Understanding. Integrating Perception, Conception and Feeling, Cambridge University Press, New York 2005. Este libro defiende la gran importancia que tienen las emociones o los afectos a la hora de explicar o interpretar la experiencia religiosa. 
el estado de conciencia por medio del que percibimos a Dios es puramente afectivo en términos de contenido fenoménico.

No obstante, se cuestiona la fiabilidad de la percepción mística cuyo contenido fenoménico es puramente afectivo. Hay una disparidad significativa entre la percepción mística y la percepción sensorial, porque solamente en el segundo caso tenemos un lenguaje para el registro del contenido fenoménico (o más exactamente, "las cualidades fenoménicas básicas") de la experiencia. Esta desemejanza es una amenaza para el proyecto de Alston, que implica que a la experiencia religiosa le puede faltar algún contenido fenoménico; por lo que podemos dudar de si tal experiencia es realmente una experiencia en absoluto ${ }^{67}$.

Aunque Alston ha manifestado el contenido afectivo de la experiencia teísta, postula una reserva continua sobre el papel del sentimiento en la experiencia religiosa. La tradición mística católica siempre conlleva algún fenómeno no afectivo. Aunque no sean sensoriales, ciertas experiencias espirituales de algún modo se parecen al tacto, mientras que otras se parecen al gusto u olfato ${ }^{68}$. Aunque los sujetos de las "percepciones místicas" describan su experiencia en términos relativos al sentimiento, los teístas que sostienen la importancia epistémica de la experiencia religiosa pueden mostrar más simpatía que Alston por el pensamiento de que el contenido fenoménico de ciertas experiencias religiosas es en gran parte (si no totalmente) afectivo. Además, la noción de un modo de intuición no sensorial y no afectiva puede resultar problemática ${ }^{69}$.

La experiencia mística puede construirse como percepción en el mismo sentido genérico del término como percepción sensorial ${ }^{70}$. Alston argumenta contra la concepción de que la experiencia mística consista simplemente en sentimientos y sensaciones subjetivas que son típicamente creídas por los sujetos que tienen una explicación sobrenatural. Además reconoce que hay una larga tradición que ha visto la experiencia

67 Wynn, Emotional, 11.

68 San Agustín, Las Confesiones, X,27,38. Dios se manifiesta y penetra por los cinco sentidos, no solamente a la vista, sino al oído, al olfato, al gusto y al tacto.

69 WynN, Emotional, 15-16.

70 BAGger, Religious, 126. La preferencia de Alston por el término "percepción mística" se refiere al hecho que subraya el paralelo con el caso de la percepción de un vegetal donde nosotros concedemos la existencia de un objeto independientemente de nuestros conceptos y participando en el suceso produciendo la experiencia. El término "experiencia religiosa", por el contrario, no presta atención inmediata a un objeto externo y deja la naturaleza del suceso a una experiencia no específica. Alston quiere incluir el concepto complejo de Dios en una posición análoga a la no controvertida, ocupada por un objeto experimentado en la percepción ordinaria. 
mística como perceptual. En el capítulo primero del libro, Alston describe una serie de experiencias en las que el mismo sujeto es consciente directamente de Dios, con un énfasis particular sobre esa subclase en la que la experiencia no es sensorial. Un escrutinio de las informaciones de tales experiencias revela que el modo de conciencia que comportaba es distintivamente perceptual; le parece al sujeto que algo (identificado por el sujeto como Dios) está presente directamente en su conciencia. Miramos otras condiciones que se toman para una u otra consideración de la percepción, necesaria para que tal experiencia constituya una percepción genuina de Dios, y concluimos que si Dios existe es posible que, al menos, algunas de estas experiencias puedan tener aquel status. La pregunta es si tales experiencias proporcionan una cierta justificación de la creencia sobre Dios. La supuesta percepción de Dios puede proporcionar justificación para ciertas creencias sobre Dios y, de ese modo, contribuir como fundamento para la creencia religiosa ${ }^{71}$.

Swinburne cree que las experiencias místicas de Dios son una prueba de que Dios entra en contacto real con los seres humanos. Cree también que cuando a esta prueba se le añaden otras, podemos tener una caso cumulativo evidencial para afirmar la existencia de Dios. Gellman defiende la validez de, al menos, algunas experiencias místicas de Dios, concluyendo que la gente por medio de la experiencia conoce realmente a Dios. Pero considera que no todo el mundo tendría que estar de acuerdo con esta conclusión, aunque muchos lo encuentren racionalmente convincente. No obstante, presenta nuevas objeciones que retan a la validez de la experiencia de Dios, al mismo tiempo que ha descubierto la importancia de las explicaciones naturalistas de las experiencias místicas de Dios 72 .

Algunos filósofos han querido deducir la existencia de Dios por la autenticidad de las percepciones de Dios. Pero de que la gente experimente a Dios genuinamente no se sigue necesariamente que Dios exista. El valor evidencial de las experiencias de Dios podía ser una cuestión abierta para el teísta. Pero la situación epistémica que para el teísta estaría justificada, no es la misma que para el no teísta. Si estuviera justificado racionalmente creer que Dios existe antes de examinar las experiencias místicas de Dios, sería epistemológicamente más fácil justificar la creencia de que la gente experimenta genuinamente a Dios. Si Dios exis-

71 Alston, Perceiving, 67.

72 Gellman, Jerome, Mystical Experience of God. A Philosophical Inquiry (=Ashgate Philosophy of Religion), Ashgate, Burlingon 2001, 1-2. 
te, es bastante plausible pensar que, en algún modo u otro, pudiera experimentarse por los seres humanos. Esta consideración presta apoyo para la autenticidad de la experiencia de Dios ${ }^{73}$.

Gellman ${ }^{74}$ entiende por experiencia mística una experiencia en la que una persona tiene una percepción aparentemente no sensorial de una realidad (o de un estado de hechos) que no puede ser percibida por la percepción sensorial ni conocida por la introspección ordinaria. Las personas cuando tienen experiencias místicas no solamente tienen tales estados perceptuales, sino que están en contacto con una realidad supra sensorial. Una experiencia mística es una "percepción" en el sentido de incluir un contenido fenoménico, presente al sujeto como una apariencia supuesta de una realidad o un estado de hechos. El contenido fenoménico posee una estructura sujeto-objeto, es decir, la experiencia incluye el sentido de que algo se hace presente al sujeto.

Decir que la experiencia mística es supuestamente una percepción "no sensorial" significa que la percepción no viene de los cinco sentidos ni del sentido interior. Hay un "sentido místico" adicional no sensorial por el que la gente puede percibir el contenido fenoménico de una clase diferente que la disponible por los sentidos ordinarios. Por no sensorial estamos pensando en un componente místico de la experiencia por sí misma, excluyendo el contenido sensorial así como las imágenes visuales o auditivas ${ }^{75}$.

Gellman defiende que el fenómeno de las experiencias místicas de Dios provee una evidencia inicial suficiente para concluir que los seres humanos experimentan a Dios genuinamente, lo que se llama la evidencia suficiente inicial de las experiencias místicas de Dios. Es decir, siguiendo el principio de credulidad de Swinburne, podemos decir que las creencias perceptuales ordinarias gozan de una evidencia suficiente, a no ser que existan razones para dudar de su validez. Por lo tanto, una persona podría justificar tales creencias como verdaderas. Del mismo modo, la experiencia mística de Dios goza también de esa misma eviden-

73 Ibid., 2-3.

${ }^{74}$ Ibid., 4.

75 Ibid., 4 y 7. La razón de Gellman para restringir el término "percepción mística" al de la percepción de realidades no disponible a los sentidos físicos es doble. Primero, la contemplación de visiones o de escuchar voces inusuales, imitando la percepción sensorial, caracteriza no solo algunas percepciones espirituales sino también varias formas de enfermedades mentales. Por esta razón hay una resistencia natural a tomar estas como indicaciones de una experiencia de una realidad objetiva. Segundo, místicos importantes han repudiado el valor de las visiones y voces inusitadas para su encuentro con Dios, sobre la base que estas no proporcionan sentido profundo de la presencia de Dios. 
cia suficiente. Por lo tanto, si la gente cree percibir a Dios, debemos asumir que ellos realmente perciben a Dios, a no ser que tengamos una razón para dudarlo. De ahí que las percepciones de Dios gocen de una evidencia suficiente ${ }^{76}$.

\section{Objeciones al enfoque de William Alston}

Desde luego que muchos creyentes tienen experiencias (M-creencias) de las indicadas anteriormente, que Dios se relaciona con ellos en los modos indicados. Entre los filósofos, sin embargo, hay una inclinación acentuada a pensar que estas experiencias no pueden ser valoradas prima facie. Al menos, se necesitaría tener una razón independiente para creer que Dios existe y que se manifiesta, antes de que fuera razonable creer que las experiencias son lo que parecen ser. Es decir, las experiencias por sí mismas, no pueden llevar el peso de la justificación de nuestras creencias.

Alston piensa que esa opinión es errónea, ya que muestra una arbitrariedad y prejuicio contra las experiencias religiosas al decir que no podemos apoyarnos en ellas para justificar las creencias religiosas. Alston defiende que si aceptamos la percepción sensorial como la base de la justificación de nuestras creencias sobre el mundo físico, entonces como un asunto de justicia y razonabilidad debemos aceptar, de la misma manera, la experiencia religiosa para justificar las creencias sobre Dios ${ }^{77}$.

La objeción que se le hace es que la experiencia religiosa no es paralela con la experiencia sensible en términos de justificación. Pues no experimentamos realmente a Dios ${ }^{78}$, podemos ser conscientes de un fuerte sentimiento subjetivo de entusiasmo o éxtasis, que se puede interpretar como la presencia de Dios. Según esta objeción, lo que se quiere decir es que las creencias sobre la presencia de Dios y su actividad deben considerarse como creencias derivadas; las creencias básicas, que están directamente justificadas por la experiencia, son creencias sobre los propios estados psicológicos 79 .

76 Ibid., 17-18.

77 Alston, Perceiving, 3.

78 Gellman, Mystical, 36. No hay manera de descubrir empíricamente que la experiencia mística de Dios es engañosa, que la gente no estaba realmente en contacto con Dios cuando pensaban que lo estaban. Sin embargo, si no hay modo posible de mostrar que una experiencia es engañosa, no es posible que la experiencia sea una evidencia positiva de su autenticidad. Por lo tanto, las experiencias místicas de Dios no pueden contar para su autenticidad.

79 Peterson, Reason, 128. 
Aunque esto mismo se podría decir sobre la experiencia sensorial. Cuando parece que ves un árbol, ese hecho por sí mismo (según esta opinión) no justifica la afirmación de conocer algo sobre el árbol; todo lo que puedes afirmar sobre la base de esa experiencia es que tienes esa clase de experiencia. Para saber que existe un árbol, un objeto real, ante nosotros, necesitamos un argumento para justificar la "interpretación" de nuestra experiencia.

Las M-creencias están directamente justificadas por la experiencia religiosa (en la terminología de Plantinga son creencias "propiamente básicas"), Alston no afirma que todas esas creencias sean verdaderas. Tanto en las M-creencias como en las creencias perceptuales ordinarias, puede haber buenas razones para concluir que "las cosas no son como parecen”. En ciertas circunstancias me puede parecer que el agua corre hacia arriba, pero otras cosas que sé sobre el mundo me disuaden de aceptar eso como verdad. Si, por ejemplo, digo que Dios me ha ordenado matar a todos los musulmanes, desobedecería educadamente esa revelación sobre la base de que el Dios cristiano nunca me daría esa orden en absoluto. Esta situación se describe mejor diciendo que la experiencia proporciona prima facie la justificación de nuestras creencias, es decir, que tales creencias deben ser aceptadas al menos que haya una razón convincente para pensar que son falsas. Y eso es verdad tanto para las creencias perceptibles como para las M-creencias ${ }^{80}$.

Sin embargo, tenemos buenas razones para pensar que la percepción sensorial es más fiable que la experiencia religiosa. Lo que percibimos por nuestros sentidos muestra un gran acuerdo de consistencia entre diferentes observadores. La experiencia sensible nos ofrece un detallado y preciso conocimiento de las cosas físicas del mundo y nos permite hacer predicciones sobre ellas con una seguridad considerable. Nada de esto es verdad en relación con la experiencia religiosa. Mucha gente no tiene tales experiencias ${ }^{81}$. Y entre aquellos que las tienen, hay gente de diferentes culturas y religiones, que experimentan a Dios con características contradictorias, y no hay modo posible de resolver esos conflictos ${ }^{82}$.

80 Alston, "Christian," 112.

81 Gellman, Mystical, 35. Mucha gente nunca es agraciada con las experiencias místicas de Dios. Por lo que, en realidad, hay mucha más gente que no tiene experiencia de Dios, que la que la tiene. La ausencia de tales experiencias en mucha gente cuenta contra la explicación teísta.

82 Ibid., 36. Dado que en las religiones aparecen visiones contrapuestas, la prudencia aconseja no aceptar las experiencias místicas de Dios como válidas. ¿Cuál es la razón para preferir las experiencias místicas de un Dios personal a las de un ser absoluto impersonal, cuando estas últimas ocurren en numerosas y diversas condiciones? 
En particular, no hay modo de hacer predicciones que sean suficientemente precisas para que sirvan como confirmación de las creencias religiosas $^{83}$.

Alston reconoce la verdad de estas quejas u objeciones, pero mantiene que ellas no socavan la experiencia religiosa como una fuente de justificación para M-creencias. No podemos tener un conocimiento detallado de Dios como tenemos de las cosas ordinarias del mundo físico, Dios es demasiado grande y misterioso, demasiado lejano, para que sea posible este conocimiento. Del mismo modo que está fuera de cuestión suponer que podemos predecir las acciones de Dios o tener de él una "experiencia contrastada". Dado que mucha gente parece no tener tales experiencias, mantenemos las enseñanzas de la mayoría de las religiones. Dios ha decretado que el ser humano sea consciente de su presencia de un modo claro e inconfundible, solo cuando se satisfacen ciertas condiciones especiales y difíciles.

De todas las objeciones, la más difícil de todas para Alston es la basada en el hecho de que personas de culturas y tradiciones religiosas dispares conciban a Dios -la experiencia de Dios- de modo muy diferente ${ }^{84}$. Una de las más llamativas, pero no la única, es la diferencia entre las religiones teístas, en las cuales Dios se experimenta como un ser personal con quien se puede entrar en una relación personal, y las religiones politeístas, como por ejemplo la forma advaita del Hinduismo, que concibe a Dios como una unidad impersonal y mantiene que la última forma de la iluminación religiosa es experimentar el hecho que no hay diferencia entre uno mismo y Dios, es decir, afirma la unidad entre las almas (atman) y la divinidad (Brahman).

83 Peterson, Reason, 129.

84 Runzo, Joseph, "Perceiving God, World-Views, and Faith: Meeting the Problem of Religious Pluralism", en SENOR, The Rationality of Belief, 243 y 245. El problema fundamental o más débil de la posición de Alston es el pluralismo religioso. Las diferentes tradiciones religiosas con sus correspondientes prácticas místicas hacen afirmaciones fundamentales que son contradictorias. Lo que todas tienen en común, según Alston, es la búsqueda de una realidad última. Gellman, Mystical,37. Gellman responde a la objeción de la diversidad de las religiones, diciendo que las experiencias místicas son mucho más pobres que las que corresponden a las experiencias de Dios. Argumenta también que la diversidad de experiencias místicas de Dios en las religiones y entre un ser personal absoluto y uno impersonal, no es razón para abandonar la evidencia de las experiencias de Dios. YANDELL, The Epistemology, 183. Cada tradición religiosa tiene su propia experiencia religiosa, por lo que la comparación de las experiencias religiosas entre las diferentes tradiciones es posible solamente en términos altamente abstractos o típicamente engañosos. Véase también Frank Davis, The Evidencial Force, 166- 192 y Alston, Perceiving, 255-285. 
Supongamos que lo que Alston ha argumentado es correcto, y que la experiencia religiosa proporciona prima facie justificación para M-creencias. Entonces por supuesto la cuestión debe plantearse, ¿De quién es la experiencia? y ¿De quién son las M-creencias? Ambas creencias, la Mcreencia teísta que la persona entra en comunión de amor con Dios y la advaita M-creencia que la persona (atman) no se distingue del Brahman están prima facie justificadas. Pero ambas creencias no pueden ser verdad al mismo tiempo. Y el modo de vida religiosa será totalmente diferente dependiendo del camino que aceptemos.

Parecería que la afirmación más importante y central de la epistemología reformada es que la experiencia religiosa juega un papel independiente en la justificación de las creencias religiosas; y que no se requiere un argumento anterior para mostrar que tal experiencia sea fiable. Además, las creencias enraizadas en la experiencia religiosa son creencias básicas, como las creencias enraizadas en la experiencia sensorial también lo son. Resumiendo, en la afirmación de Plantinga, la creencia en Dios puede ser considerada "propiamente básica ${ }^{85 " ~ y, ~ e n ~ l a ~ d e ~ A l s-~}$ ton, en nuestra experiencia religiosa "percibimos a Dios".

Incluso si se acepta la afirmación básica del epistemólogo reformado, y se considera que las experiencias religiosas juegan un papel decisivo en la justificación de las creencias religiosas, permanece el problema más importante creado por las diferentes experiencias religiosas y las interpretaciones de aquellas experiencias, en las tradiciones religiosas. Como hemos visto, Alston considera que afrontando esta situación el creyente puede apelar a la evidencia y argumentos que descansan fuera de la esfera de lo que se experimenta directamente 86 .

La epistemología reformada no considera que sus creencias fundamentales estén exentas de la evaluación racional, al contrario, la mencionada evaluación es bienvenida. Los epistemólogos reformados están muy preocupados por considerar y responder a las pruebas y argumentos contra la existencia de Dios - por ejemplo, el problema del mal-. Su posición

85 Frank Davis, The Evidencial Force, 87-89. El argumento de Plantinga de que la creencia en Dios aparece como una creencia básica porque es generado por experiencias religiosas que son fiables. Partiendo de la afirmación de Calvino que "Dios ha implantado en nosotros una tendencia natural para ver su mano en el mundo que nos rodea", muestra pues la disposición natural a creer en Dios con ejemplos de la experiencia religiosa: el universo inmenso ha sido creado por Dios, leyendo la Biblia uno puede ser impresionado con un sentido profundo de que Dios le habla, o puede sentirse culpable a los ojos de Dios pues cree que Dios desaprueba lo que ha hecho, etc. Como podemos ver la creencia básica no es la existencia de Dios, sino las anteriores, pero de ellas se concluye que Dios existe.

86 Peterson, Reason, 130-131. 
requiere hacer esto, porque la justificación conferida por la experiencia religiosa es solamente una justificación prima facie; y podría ser invalidada si hubiera razones irresistibles, que proceden de otra fuente, mostrando que Dios no existe. Por eso necesitan mostrar que no existen esas convincentes razones contra la existencia de Dios.

\section{VI. ¿PUede la eXPerienCia Religiosa Justificar la CREenCIa Religiosa?}

Se puede afirmar que las experiencias religiosas desempeñan un papel inestimable para justificar las creencias religiosas de la gente. Como decía un cartel, “¡Dios no está muerto -hablé con él esta mañana-!”. Pero si la alegada experiencia de Dios puede usarse como fundamento para justificar nuestras creencias depende, en parte, de cómo se caracteriza la experiencia religiosa.

Cada vez es más aceptado entre los filósofos de la religión que la experiencia religiosa tiene un papel importante en la justificación de la creencia religiosa. Sin embargo, es muy discutido saber qué papel, o cómo podemos conceptualizar mejor la contribución de la experiencia religiosa a la racionalidad de la creencia religiosa ${ }^{87}$.

Primero, supongamos que la experiencia religiosa es un sentimiento. Según Schleiermacher los sentimientos no sólo generan la estructura de la creencia religiosa sino que también la justifican. Pero, ¿pueden los sentimientos justificar las creencias cognitivas? La dificultad surge de la afirmación que ambos, Dios (como trascendente) y nuestra experiencia de Dios (como sentimiento, no estructurado por conceptos y creencias) son inefables. Pero para que la experiencia tenga una significación cognitiva, debe estar asentada en creencias y conceptos racionales ${ }^{88}$.

Quienes describen la experiencia religiosa como un sentimiento se encuentran con un dilema. Si la experiencia religiosa es inefable, entonces no puede usarse para fundamentar las creencias, no hay contenido racional para proporcionar la fundamentación ${ }^{89}$. Sin embargo, si la expe-

${ }^{87}$ HASKer, “The Epistemic Value,” 150.

88 Peterson, Reason, 26.

${ }^{89}$ Franks DAvIs, The Evidential Force, 14. Si las experiencias religiosas son inefables, ninguna afirmación cognitiva se puede basar en ellas, y, por lo tanto, las experiencias religiosas no serían apropiadas para la justificación de las creencias religiosas. Franks Davis defiende que hay experiencias religiosas, particularmente las místicas (de hecho hay algunas experiencias místicas tan inefables que son realmente no cognitivas), que se pre- 
riencia tiene un contenido conceptual, entonces no puede ser independiente de la expresión conceptual e inmune de la crítica racional.

En general, entendemos la experiencia religiosa sobrenatural, es decir, el experimentador cree que la experiencia no puede explicarse por causas naturales. La designación de una experiencia como religiosa requiere que los que tienen la experiencia tengan ciertas creencias e identifiquen esas creencias como la causa de la experiencia. Pero entonces la experiencia religiosa no puede usarse para justificar la creencia en la existencia de esa causa. Hacer eso sería una argumentación circular: la experiencia es religiosa porque alguien la percibe como causada por Dios; y esa persona tiene buenas razones para creer que Dios existe por su experiencia religiosa. Por lo que, si utilizamos la experiencia religiosa para demostrar la realidad de lo misterioso, estamos argumentando circularmente, pues solamente se explica la experiencia religiosa desde la irrupción del misterio. Y eso es, precisamente, lo que pretendemos demostrar por medio de la experiencia religiosa.

El argumento aquí es similar al comúnmente dado en relación a lo que los milagros pueden y no pueden mostrar. Si los milagros se definen, como sucesos causados por Dios, no pueden usarse para probar la existencia de Dios. La misma existencia de Dios ha sido adoptada para identificar la experiencia como milagrosa. De modo similar, si la experiencia religiosa se define en términos de una causa sobrenatural, entonces esa experiencia no puede usarse para justificar la creencia en esa causa.

La experiencia religiosa es significativa en la medida que encuentra su lugar dentro del mundo religioso de la persona que tiene la mencionada experiencia. La cual tiene sentido porque la persona posee ya un tipo de creencias en la que se incluye lo sobrenatural. Esta creencia no se deduce o fundamenta en la experiencia, sino que es parte de la misma descripción y, por lo tanto, una presuposición de la experiencia.

Una experiencia se manifiesta como religiosa si el experimentador puede comprender o explicar la experiencia separada de lo sobrenatural. Si esto es así, entonces hay al menos una explicación del acontecimiento en que es prima facie razonable y requiere la existencia de Dios. Esto no

sentan como inefables, pero, no son inefables en el sentido radical de que no podrían ser experiencias cognitivas. YANDELL, The Epistemology, 9. Las consideraciones filosóficas y religiosas apoyan la tesis de que la experiencia religiosa es inefable. Y lo que es inefable no se puede describir. Yandell critica las afirmaciones de que las experiencias religiosas sean inefables, pues entonces no servirían para justificar las creencias religiosas. Tampoco podemos decir que Dios sea completamente inefable, pues no podríamos hablar de él, ni siquiera afirmar su existencia. 
excluiría la posibilidad que alguien más fuera capaz de proporcionar una explicación completa y naturalista del suceso. Sin embargo, cuantas más experiencias puedan explicarse de modo convincente apelando a lo sobrenatural, y cuantas más experiencias se ajusten a una estructura coherente, hacen que la explicación sea correcta. Es decir, la consideración más coherente, y la llamada a lo sobrenatural explica ciertas experiencias, la carga de la prueba caería en la persona que negaba la veracidad de la experiencia diciendo que Dios no era la causa.

En otras palabras, si nuestras experiencias no pueden usarse para justificar las creencias, entonces ninguna de aquellas pueden justificar nuestras creencias; en esta comprensión todas las experiencias invocan nuestras estructuras creenciales. Esto significaría que mi experiencia de ver un gato en el árbol no justificaría la creencia que hay un gato en el árbol, y presupondría que hay tales cosas como gatos en los árboles. Pero, ¿Qué justificaría esta creencia? Tal punto de vista, dejaría todas las creencias experimentales como injustificables.

Finalmente, quienes sostienen que la experiencia religiosa es perceptual argumentan que la experiencia religiosa puede usarse para justificar las creencias religiosas. Comúnmente usamos nuestras percepciones para justificar nuestras creencias sobre el mundo. Por ejemplo, justificamos que hay un petirrojo en el césped, cuando vemos un petirrojo allí y no tenemos razón para pensar que las condiciones perceptuales están fuera de lo común. De modo semejante, las personas religiosas justifican que Dios existe, les ama y responde a sus oraciones apoyados en sus experiencias religiosas. Swinburne ${ }^{90}$ llama a esto el principio de credulidad: cuando a alguien le parece que algo es el caso, es probablemente así, a no ser que haya consideraciones especiales para atemperar la afirmación. Es decir, el modo como las cosas se nos muestran nos proporcionan buenas razones para creer que así es cómo son en realidad. Justificamos dicha creencia hasta que no sean introducidas consideraciones contrarias que arrojarían duda sobre dicha percepción particular o el funcionamiento preciso de nuestro aparato perceptual en general. Esto no significa que no podamos equivocarnos sobre la experiencia, pero coloca la carga de la prueba sobre quienes afirman que la experiencia no es genuina.

De modo semejante, en ausencia de consideraciones especiales, la experiencia religiosa debe tomarse, por los experimentadores, como proporcionando buenas razones para creer que Dios o la Realidad Última existen. Esto no significa que los experimentadores no puedan equivo-

90 Swinburne, La existencia, 339-340. 
carse en su creencia. Pero igual que las percepciones ordinarias, las personas mantienen su creencia hasta que se den buenas razones para pensar que la creencia esté reñida con otras creencias (por ejemplo, sobre la naturaleza y el carácter de Dios) o que hay algún defecto en el aparato perceptual. La experiencia religiosa proporciona prima facie la justificación de las creencias sobre Dios ${ }^{91}$.

La persona que ha tenido una experiencia religiosa de Dios, por el principio de credulidad, tiene buenas razones para creer que Dios existe, especialmente si es una experiencia intensa. La fuerza evidencial de la experiencia religiosa depende del principio de credulidad, las percepciones deben ser tomadas como se nos aparecen, en ausencia de una razón positiva para su recusación ${ }^{92}$.

Pero ¿podemos aceptar el principio de credulidad? Un problema es que mientras hay una uniformidad fundamental sobre el modo en que informamos de las experiencias perceptuales ordinarias y de las creencias sobre objetos de aquellas experiencias, hay bastante diversidad de información sobre las experiencias religiosas y las afirmaciones basadas en ellas. Como ya hemos afirmado, las personas ofrecen descripciones incompatibles sobre la Realidad experimentada. Por ejemplo, los cristianos describen a Dios como trinidad y realmente distinto de ellos, mientras los hindúes caracterizan a Brahmán como la totalidad de la realidad y describen la relación del self (atman) con el Brahmán de un modo no dualístico.

Swinburne formula a su vez el principio del testimonio ${ }^{93}$ que completa en cierto modo el de credulidad. Muchas personas nos dicen que tienen experiencias religiosas y normalmente no hay consideraciones especiales para dudar de lo que nos exponen sobre ellas. Por lo tanto, en ausencia de consideraciones especiales, las experiencias religiosas de otras personas son (probablemente) como ellos las presentan.

91 Peterson, Reason, 28. Hick, "The Rationality," 308. Del mismo modo que en la experiencia normal podemos adoptar el principio general de que en ausencia de fundamentos adecuados para la duda, es racional el confiar en nuestra experiencia del mundo externo. Y, por el contrario, sería una locura creer, sin una cierta razón, en algo que se nos aparece a nuestra experiencia sin una existencia objetiva y, además, que no se ajusta a nuestras creencias sobre el entorno.

92 Swinburne, La existencia, 364-365.

93 Ibid., 360-361. GeIVETT, "The Evidential Value," 508-509. El principio del testimonio combinado con el principio de credulidad llega a la siguiente conclusión: Si las cosas son como la gente normalmente las percibe, la aceptación del testimonio de tener experiencias religiosas nos lleva a aceptar que estas experiencias religiosas son experiencias de Dios y, por lo tanto, que Dios existe... 
No obstante, también hay críticas al principio del testimonio, normalmente para cuestiones de gran importancia, los estándares para la aceptación del testimonio de otros será indudablemente muy alta. En este sentido, podemos decir que los estándares para la aceptación de la existencia de Dios por el testimonio de otros serán mucho más altos que para otras situaciones. También podemos ver cómo las experiencias de Dios son realmente variadas. Esta pluralidad de experiencias revela la presencia de concepciones contrarias que surgen de las experiencias de Dios $^{94}$. Tal vez la fuerza de la evidencia del testimonio, en relación con las experiencias de Dios, esté viciado igualmente por los numerosos relatos de las experiencias religiosas no teístas ${ }^{95}$.

Volviendo al principio del testimonio, Geivett ${ }^{96}$ recomienda una comprensión de la naturaleza y significado del testimonio más extenso. La evidencia testimonial debe medirse en relación a la credibilidad del testigo que va en función del carácter y experiencia del mismo. En relación al carácter, varias virtudes son relevantes, pero la honestidad es especialmente importante. En relación con la experiencia, debe ser la confianza que un testigo tiene una habilidad mínima para comprender lo que está relacionado con su testimonio y puede hablar sobre él de forma inteligente y con exactitud. Los frutos morales de la experiencia religiosa en las vidas de los sujetos conciernen a ambas dimensiones de la credibilidad. Todas estas condiciones de la credibilidad del testimonio tienen que ser discutidas al hablar de la experiencia religiosa.

Entre las personas que podemos admirar por la devoción espiritual y en las que podemos confiar por su testimonio sobre la experiencia de Dios, hay preponderancia de las que han tenido a Jesús de Nazaret como modelo. En efecto, la influencia de la persona de Jesús en la vida de muchas personas en las diversas culturas debe provocar una curiosidad sobre la posible verificabilidad de las invocadas experiencias de Dios. Un cierto sentimiento de lo expuesto sobre la relación con la persona y la enseñanza de Jesús se presentan comúnmente como experiencia religiosa que puede ser compartida tanto por creyentes como por no creyentes. Podemos concluir con el testimonio de los discípulos que seguían y cono-

${ }^{94}$ Ibid., 514. Una objeción a la evidencia de la experiencia religiosa para la existencia de Dios es la diversidad religiosa. Podemos distinguir entre las experiencias religiosas en las que Dios es reconocido por el sujeto y aquellas experiencias donde Dios no es reconocido. Otra objeción es que las experiencias religiosas pueden explicarse tan bien, o mejor, en términos aceptables a la metafísica naturalista. Muchas de esas experiencias obedecen o se pueden explicar cómo patologías psicológicas.

95 Ibid., 513.

96 Ibid., 518. 
cían a Jesús más íntimamente. La presencia en sus vidas fue tan transformadora que aplicaban el lenguaje más exaltado que podían encontrar para expresarlo, lenguaje que va unido con los destinos personales al poder de su presencia ${ }^{97}$.

¿Pueden reconciliarse todas estas perspectivas religiosas?, especialmente si se apoyan en creencias contrarias o contradictorias. Quizás ellas no puedan, pero esto que se argumenta, no es funesto para el principio de credulidad. El principio no comporta que todas las percepciones deban ser verídicas. Cuando las percepciones producen testimonios conflictivos, debemos volver a otras experiencias y argumentos racionales para determinar la verdad de varias afirmaciones. Es decir, cuando hay diferentes consideraciones, se debe buscar ayuda para decidir si alguna de las experiencias religiosas es verídica. Aunque los informes proporcionen prima facie una fundamentación para su aceptación, no todas las creencias basadas en tales experiencias son verdaderas. Justamente dudamos de las afirmaciones perceptuales por buenas razones; podríamos hacer lo mismo de las afirmaciones basadas en la experiencia religiosa. En consecuencia, las creencias justificadas sobre Dios y las prácticas religiosas sería un modo de eliminar las afirmaciones menos fiables.

Alguien podría sorprenderse, sin embargo, si esta respuesta hace justicia a la diversidad de afirmaciones sobre la Realidad misteriosa que es percibida por la experiencia religiosa. Si personas en varias tradiciones informan sobre las experiencias religiosas, y si estas tradiciones contienen visiones radicalmente incompatibles sobre el mundo, ¿qué justificación puede proporcionar la experiencia religiosa para alguna creencia particular?

Obviamente, muchos puntos necesitan aclararse si aceptamos la tesis de que la experiencia religiosa es una experiencia perceptual que puede justificar las creencias religiosas. El principio de credulidad necesita revisarse. Nos podríamos preguntar, por ejemplo, si este principio debe aplicarse del mismo modo a todas las afirmaciones perceptuales ${ }^{98}$. En suma, el significado de la diversidad de informaciones sobre la experiencia religiosa y las afirmaciones conflictivas a las que da lugar debe ser investigado. Esto sugiere que la justificación de la creencia religiosa debe abordarse desde distintas direcciones ${ }^{99}$.

97 Ibid., 519.

98 Ibid., 518. Aunque hay diferencias entre la percepción sensible y la percepción de Dios, estas diferencias no afectan a la aplicabilidad del principio de credulidad para las experiencias de Dios. Este principio es más generalizable que lo que se reconoce en la mayoría de las discusiones. De hecho, es difícil pensar un contexto en el que no se aplica.

99 Peterson, Reason, 29. 


\section{Conclusión}

Como hemos intentado mostrar a lo largo del estudio, la experiencia religiosa nos ayuda a dar razón de nuestras creencias religiosas. Una de estas experiencias religiosas, en la que hemos insistido, es la percepción directa de Dios, la persona que ha tenido dicha experiencia perceptiva está justificada en tener ciertas creencias referidas a Dios. El libro de Alston, Perceiving God, concluye con un ejemplo que contribuye a ampliar nuestra perspectiva, lo que él llama un argumento cumulativo.

Nos presenta a una persona llamada Denise que ha recibido una buena educación cristiana y ha vivido esa fe desde su más tierna infancia; pero al llegar a una cierta edad se cuestiona su fe. Siendo consciente de la diversidad de religiones, se pregunta por qué debía suponer que la religión cristiana es más verdadera que el resto; cuestiona la apologética tradicional cristiana que apela a los milagros, el cumplimiento de las profecías, el crecimiento de la Iglesia, etc. Estudia también los argumentos tradicionales para la existencia de Dios y, aunque le parecen aceptables, no son lo suficientemente sólidos para sostener todo el edificio.

En este proceso reflexiona sobre su propia experiencia de vida cristiana. Ella experimenta frecuentemente la presencia de Dios derramándole su amor, sosteniéndola en su ser y transformándola en la persona que tendría que ser. Se pregunta si esta relación con Dios puede ser un fundamento para su fe. Denise reconoce las dudas sobre la fuerza epistémica de estas experiencias y siente que su última seguridad se le viene abajo.

Pero, inspirada por los estudios de la epistemología religiosa contemporánea, tiene una ocurrencia nueva. Quizás sea un error buscar un fundamento para la fe, que sea infalible, indudable e incorregible basado en la propia experiencia, sin necesidad de apoyarse en alguna otra fuente. Tal vez lo más razonable sea tener diversos puntos de apoyo, y así, aunque cada uno puede ser cuestionado, siempre quedarán otros en los que sostenerse, pues ninguno es suficiente por sí mismo. Solamente desde este armazón encontramos razones suficientes para aceptar las creencias como verdaderas. Todas las razones en conjunto nos permiten aceptar sensatamente una creencia como verdadera ${ }^{100}$.

Para afirmar la existencia de Dios se puede apelar al testimonio ${ }^{101}$ de quienes tienen más experiencia en la vida cristiana, a la revelación de

100 Alston, Perceiving, 300-301; STOKER, Is Faith, 59-60.

101 STOKER, Is Faith, 62. Generalmente aceptamos muchas cosas en la vida apoyados en el testimonio de los testigos. Alston argumenta correctamente al decir que tal percep- 
Dios en los acontecimientos históricos, y a las razones filosóficas. Y aunque es cierto que se puede dudar de cada una de estas consideraciones en particular, tomadas todas en su totalidad tienen mucha más fuerza. Al mismo tiempo, el creyente puede añadir otras, tales como la oración escuchada, la experiencia de vivir una nueva vida por medio del Espíritu, el testimonio de otros. Apoyados en diferentes fundamentos encontramos la razón suficiente para comprender la propia fe como verdadera.

Así tenemos que el llamado caso cumulativo ${ }^{102}$ y la perspectiva de la ayuda mutua entre los fundamentos de las creencias cristianas son superiores al apoyarse sobre una base particular, pues siempre estará sujeta a serias dudas que no pueden resolverse satisfactoriamente con los propios recursos. Es cierto que a lo largo del trabajo hemos insistido mucho sobre los méritos de la experiencia religiosa, como un fundamento particular. Pero, con este ejemplo, queremos decir que es preferible integrar la experiencia religiosa cristiana dentro de un cuadro más general para llegar a una mejor racionalidad de la creencia cristiana.

Alston, por medio del argumento cumulativo, quiere proporcionar una razón positiva para aceptar la fe cristiana como una forma práctica de vida. Las percepciones directas de Dios se basan en extendidas creencias profundas. ¿Cómo podríamos de otro modo identificar que percibimos a Dios? Nosotros tenemos la experiencia del Dios cristiano porque estamos en esa tradición de fe. Las percepciones individuales directas están enraizadas en la práctica de la fe cristiana. No es solamente una percepción directa de Dios sino también hablar con Dios en la oración y estar sujetos a prácticas litúrgicas lo que nos permite ver el mundo a la luz de Dios.

Un argumento cumulativo no es, por lo tanto, meramente una acumulación de evidencias. El todo es más grande que la suma de las partes, y estas "partes", aunque quizás sean débiles individualmente como evi-

ción directa de Dios es también autoritativa para algunos. La fe cristiana, primero de todo, es cuestión de testimonio, que es directo para aquellos que han tenido una experiencia directa de Dios, e indirecto para aquellos que aceptan el testimonio de los primeros. AlsTON, Perceiving, 281.

102 STOKER, Is Faith, 77. Stoker ve las semejanza entre el argumento cumulativo de Alston con el de Basil Mitchell en The Justification of Religious Belief. Mitchel comienza diciendo que el teísmo no puede ser probado por las pruebas de la existencia de Dios, pero tampoco puede demostrarse que el teísmo sea incoherente. En lugar de dar pruebas para la existencia de Dios, desarrolla un argumento cumulativo que consiste en tomar un número de razones conjuntamente para justificar el teísmo. Diferentes argumentos para la fe apuntan en la misma dirección, al teísmo. De este modo, se refuerzan unos a otros para apoyar el teísmo, sin que sea necesario la lógica contundente requerida por el fundacionalismo clásico. 
dencia y fácilmente derrotadas, se apoyan mutuamente, como los miembros de un equipo atlético. Esto significa que la fuerza de un argumento cumulativo no será apreciado si sus elementos son valorados aisladamente o se utilizan para construir uno sobre uno en forma lineal, como enlaces en una cadena deductiva ${ }^{103}$.

Swinburne reconoce la importancia de los argumentos cumulativos a favor del teísmo, pero no presta una atención adecuada, pues pueden también ser usados por "la otra parte". Intenta mostrar solamente que cada desafío, considerado por sí mismo, es demasiado débil para derrotar la evidencia de las experiencias religiosas. Pero los escépticos pueden también combinar aquellos desafíos y presentar un argumento cumulativo, que sea mucho más difícil de derrotar ${ }^{104}$.

Swinburne quiere mostrar no sólo que la actual creencia religiosa es racional, sino también "que el teísmo es más probable que el ateísmo". Reconoce que la experiencia religiosa por sí misma no puede llegar a una conclusión tan ambiciosa, pero no obstante juega un papel crucial en un argumento cumulativo para la existencia de Dios. Es decir, la evidencia de la experiencia religiosa es suficiente para inclinar la balanza y hacer que sea más probable la existencia que la no existencia de Dios. Swinburne llega a la conclusión de que el teísmo no es improbable, si a esto añadimos la evidencia de la experiencia religiosa, sería suficiente para hacer del teísmo, por lo menos probable 105 .

$\mathrm{El}$ argumento cumulativo teísta proveerá mucho más que simple ayuda adicional para las afirmaciones religiosas experienciales. Uno debe recordar que las diferentes piezas de evidencia interactúan en argumentos cumulativos, por lo tanto, el todo es más grande que la suma de las partes. Otros tipos de evidencia nos ayudan a explicar las experiencias religiosas e incrementar la probabilidad de que sean verídicas; las experiencias religiosas contribuyen a dar sentido a otras experiencias y creencias e incrementar la probabilidad de que ciertas creencias son verdaderas, y todas evidencias trabajan juntas para apoyar una cadena de creencias autorizadas ${ }^{106}$.

Dios ha sido experimentado a través de la historia por gran número de personas en las mayores religiones del mundo. Esto está claramente

103 Franks Davis, The Evidential, 109.

104 Ibid., 113.

105 Ibid., 93 y 95.

106 Ibid., 241. STOKeR, Is Faith, 202. La percepción directa puede ser justificada inmediatamente, porque tiene un aspecto objetivo en el que Dios se presenta a sí mismo al creyente. La percepción directa e indirecta de Dios y las experiencias religiosas duraderas constituyen una razón positiva, un argumento cumulativo para tener fe. 
atestiguado en la Biblia, en otros textos religiosos, y por numerosos reportajes y descripciones de las experiencias de la gente. Por lo tanto, hay gran número de personas, de distintas culturas y religiones, a lo largo de toda la historia que han atestiguado la experiencia de Dios y desde ahí han afirmado que es racional creer que Dios se experimenta, y por eso consideran que la creencia en Dios es racional y, finalmente, deducen la existencia de Dios ${ }^{107}$.

En el mundo global en el que vivimos, el cristianismo ha perdido la posición central y se ha convertido en una fe minoritaria. Y la misma sociedad occidental, por la presencia de otras religiones, como el Islam, Hinduismo, Budismo, etc., ha llegado a ser pluralista. Aunque cada persona tenga su fe en el ámbito privado es necesario que en la esfera pública las personas de las diferentes religiones participen en el diálogo sobre las diferentes formas de ver el mundo por el bien y la concordia en la sociedad.

No obstante, hemos de decir que la visión de Dios en la fe cristiana está en conflicto y no puede reconciliarse con, por ejemplo, la del budismo y con alguna de las tradiciones del hinduismo. El principio de presunción puede formularse como sigue: es racional aprobar algo al menos que haya una alternativa mejor. Por eso nos preguntamos si el judaísmo, el islam, el hinduismo o el budismo son una mejor alternativa que el cristianismo. El problema es que no hay criterios generales sobre la base de que se pueda decidir qué religión es la verdadera. La cuestión de la verdad en relación a la religión y las diferentes visiones del mundo no puede decidirse definitivamente, ninguna religión o visión del mundo puede excluir a las otras religiones o modos de ver el mundo. Las razones que se dan para la propia fe son, después de todo, intrínsecas, se derivan de la propia religión. La racionalidad no puede garantizar la verdad. Por lo tanto, no es razonable creer que uno tiene toda la verdad y que los otros no, como los fundamentalistas ${ }^{108}$. Miembros de otras religiones pueden hacer una presentación semejante a la que hemos hecho nosotros de la fe cristiana.

La cuestión de la verdad no puede decidirse tan rápida y fácilmente, lo cual no es una razón para dejar de considerar la propia religión como la verdadera. Desde mi punto de vista, Alston ${ }^{109}$ tiene razón cuando argumenta que es racional estar apegado a la propia tradición, y en

107 Gellman, Jerome, Experience of God and the Rationality of Theistic Belief, Cornell Press, New York 1997, 4 y 11.

108 STOKER, Is Faith, 241-242. 
ausencia de alguna razón externa para suponer que una de las prácticas rivales son más seguras que la mía, el único rumbo racional para mí es estar tranquilo con la práctica a la que pertenezco y me sirve mucho para guiar mi actividad en el mundo. Por lo tanto, lo racional para un cristiano es vivir conforme al sistema de creencias cristianas, aunque esto mismo se podría aplicar al creyente de otra religión o cosmovisión.

Una justificación de la fe cristiana dando una razón positiva para ella son los frutos que se siguen de la vida de fe, es decir, a un árbol se le conoce por sus frutos, o como dice el Evangelio "por sus frutos los conoceréis". Una fe es verdadera si en su vivencia práctica es coherente. Para Pablo, la vida en el Espíritu es la participación en la nueva era que ha comenzado en Jesús. Hay que vivir confiando en la promesa de la definitiva venida del Reino de Dios. La verdad de la fe cristiana será -y esa es la promesa- confirmada definitivamente solamente en el eschaton, cuando llegue el Reino de Dios ${ }^{110}$, es decir, la llamada verificación escatológica, pero mientras tanto la coherencia práctica ayuda a dar credibilidad a la fe.

Volvemos a la pregunta del comienzo, ¿es racional creer o tener fe? ¿Pueden los cristianos justificar racionalmente sus creencias? Por ejemplo, ¿pueden justificar que han experimentado la salvación de Dios por medio de Jesucristo? O tendremos que responder diciendo que tal experiencia de Dios es muy personal y está más allá de la racionalidad ${ }^{111}$. El creyente afirma que su creencia es racional. Y lo que hemos querido exponer a lo largo del trabajo es que uno de los caminos para la justificación de la fe es la experiencia religiosa.

La experiencia religiosa y la racionalidad son algo que tenemos que considerar normal dentro de la vida de cada día, no son cosas desmesuradas o tan profundas que no están al alcance de la vida de las personas ordinarias. Cuando hablamos de experiencia religiosa no nos referimos a experiencias místicas extraordinarias que solamente puede tener alguna persona, ni tampoco, al hablar de racionalidad, nos estamos refiriendo a un asunto exclusivamente científico, sino una cuestión propia de la vida de cada día. Por lo tanto, podemos argumentar o justificar que nuestra experiencia de Dios más común en la actualidad proviene de la lectura de la Biblia, la tradición y la comunidad de fe a la que pertenecemos y en la que vivimos. Allí es donde la mayoría de los cristianos viven y fortale-

\footnotetext{
109 Alston, Perceiving, 274.

110 STOKER, Is Faith, 242.

111 Ibid., 201.
} 
cen su fe. Por lo tanto, para el creyente cristiano la experiencia y vivencia religiosa son prácticas y razones para justificar su fe.

En el contexto particular de la experiencia religiosa podemos ver una interrelación de la experiencia religiosa con la vida de la comunidad cristiana y el comportamiento ético. Por lo tanto, los tres elementos vistos en su conjunto nos ayudan a que la creencia en Dios tenga diversos apoyos, y así, podamos creer en él más razonablemente. La experiencia religiosa, la vida moral y la litúrgica se verifican entre sí y se convierten en los fundamentos para la vida cristiana. A lo largo de la historia, la experiencia religiosa ha tenido una dimensión más comunitaria y eclesial y ha servido para verificar la fe. En la actualidad, tanto la experiencia religiosa como la dimensión ética tienen un sentido más autónomo e individual, pero en el contexto de la experiencia religiosa cristiana, tenemos que seguir insistiendo que no se puede desligar de la vida litúrgica y de la ética. En nuestra vida no podemos separar la experiencia religiosa de la vivencia litúrgica en la comunidad cristiana y del comportamiento ético diario. Los tres elementos están interconectados y todos ellos, si los vivimos coherentemente, ayudan a que nuestra fe sea más razonable y creíble. 